\title{
Psychological Impact of Cyberbully Victimization among College Students
}

\author{
Allison M. Schenk \\ West Virginia University
}

Follow this and additional works at: https://researchrepository.wvu.edu/etd

\section{Recommended Citation}

Schenk, Allison M., "Psychological Impact of Cyberbully Victimization among College Students" (2011). Graduate Theses, Dissertations, and Problem Reports. 3293.

https://researchrepository.wvu.edu/etd/3293

This Thesis is protected by copyright and/or related rights. It has been brought to you by the The Research Repository @ WVU with permission from the rights-holder(s). You are free to use this Thesis in any way that is permitted by the copyright and related rights legislation that applies to your use. For other uses you must obtain permission from the rights-holder(s) directly, unless additional rights are indicated by a Creative Commons license in the record and/ or on the work itself. This Thesis has been accepted for inclusion in WVU Graduate Theses, Dissertations, and Problem Reports collection by an authorized administrator of The Research Repository @ WVU. For more information, please contact researchrepository@mail.wvu.edu. 
Psychological Impact of Cyberbully Victimization among College Students

\author{
Allison M. Schenk \\ A THESIS \\ Submitted to the Eberly College of Arts and Sciences \\ at West Virginia University \\ in partial fulfillment of the requirement for the degree of
}

Master of Science

in

Psychology

William Fremouw, Ph.D., Chair

Amy Fiske, Ph.D.

Aaron Metzger, Ph.D.

Department of Psychology

Morgantown, West Virginia

2011

Keywords: cyberbullying, cyberbully victimization, prevalence, impact, coping 


\title{
ABSTRACT \\ Psychological Impact of Cyberbully Victimization among College Students
}

\begin{abstract}
Allison M. Schenk
With the growth of technology, bullying has expanded into the technological realm. Labeled cyberbullying, individuals are utilizing technology, such as cell phones and the Internet, to bully and harass others with the intention of causing harm. Most cyberbullying research has been conducted with elementary, middle, and high school-aged students in countries such as Finland, Canada, Taiwan, and Australia. The purpose of this study was to expand prevalence, psychological impact, and coping strategy research with college-student victims of cyberbullying in the United States. 799 college students from a mid-Atlantic university were surveyed via the Internet. It was found that $8.6 \%$ of that sample endorsed being a victim of cyberbullying; $8.7 \%$ of females and $8.4 \%$ of males. On the Symptom Checklist-90-R, the 69 victims were higher than 69 matched control participants in depression, anxiety, phobic anxiety, and paranoia, as well as were elevated on global severity index and positive symptom distress index scales. Victims endorsed frequently experiencing emotional consequences, such as feeling frustrated, stressed, $\mathrm{sad} /$ hurt, or angry. Victims had significantly more suicidal planning and attempts, as well as suicidal ideations. They also more frequently threatened suicide than control participants. In response to cyberbully victimization, female and male victims both told someone they were being victimized, avoided friends or peers, got revenge, and stopped going to events they once enjoyed. Female victims more frequently avoided Internet/cell phones and males more frequently drank alcohol/used illegal drugs as a result of their victimization. The results of this study indicated that cyberbullying is occurring in a college sample and having a negative impact upon victims.
\end{abstract}




\section{ACKNOWLEDGEMENTS}

I wish to thank many people who contributed to this project. I am extremely appreciative of Dr. William Fremouw, my academic advisor and thesis chair, for his endless support, guidance, and dedication to my academic and professional development. Additionally, I am thankful for the valuable comments, insights, and suggestions offered by my committee members, Drs. Amy Fiske and Aaron Metzger. I would especially like to acknowledge and thank my parents who have always supported and encouraged my goals and aspirations, for which I am infinitely gratefully. 


\section{TABLE OF CONTENTS}

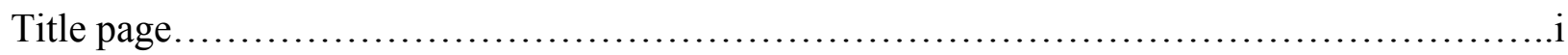

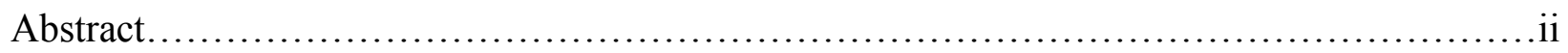

Acknowledgements............................................................. iii

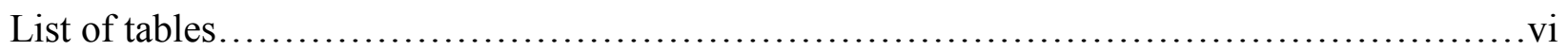

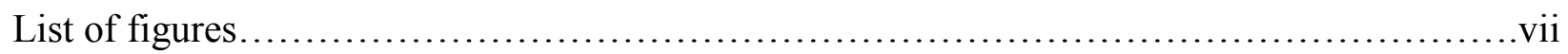

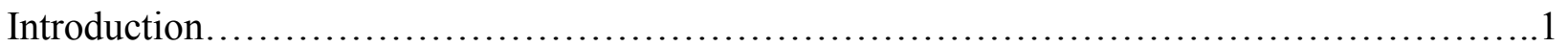

Defining Traditional Bullying and Cyberbullying.................................2

Prevalence Rates of Cyberbullying............................................4

Theories of Bullying and Cyberbullying......................................... 8

Impact of Cyberbully Victimization......................................... 11

Methods for Coping with Cyberbully Victimization..............................14

Purpose and Hypotheses.................................................. 15

Purpose 1: Prevalence of Cyberbullying in College...........................15

Purpose 2: Psychological and Behavioral Impact.......................... 15

Purpose 3: Exploratory Analyses....................................... 16

a) Suicidal Propensities..........................................16

b) Personality Differences.........................................16

c) Impact Differences.......................................... 16

Purpose 4: Coping Strategies......................................... 16

Purpose 5: Gender Differences........................................ 17



Participants........................................................... 17 


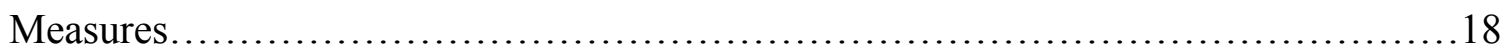

Procedure...............................................................22

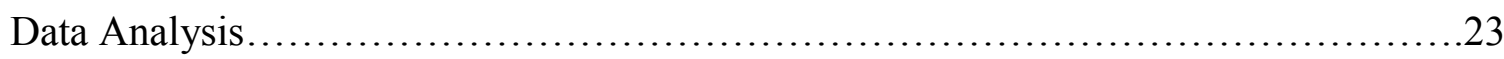

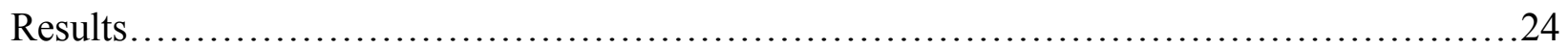

Prevalence of Cyberbully Victimization.......................................24

Psychological Impact..................................................... 24

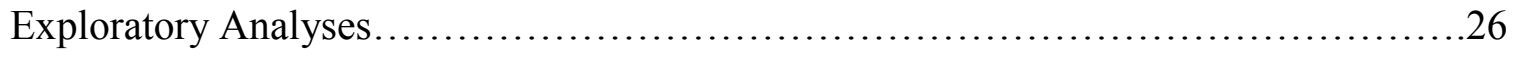

Suicidal Propensities.................................................26

Personality Differences............................................27

Impact Differences.............................................27

Coping Strategies.......................................................28

Additional Characteristics of Cyberbully Victimization Experiences...................29

Discussion......................................................................

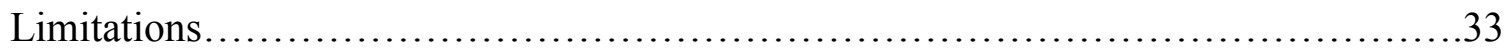

Implications of Results................................................. 34

Future Research Directions............................................... 35

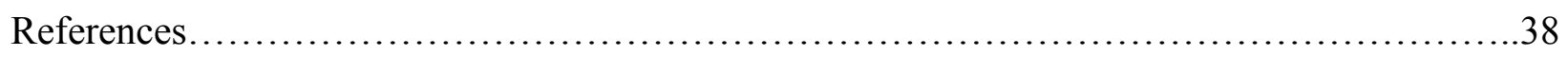

Figures..................................................................... 44

Tables....................................................................... 45






\section{LIST OF TABLES}

1. Descriptive Data for Cyberbully Victims and the Control Group.....................45

2. Means for the Symptom Checklist-90-Revised (SCL-90-R) Subscales and Additional Scales for Cyberbully Victims and Control Group..............................46

3. Impact of Cyberbully Victimization as Derived from the Internet Experiences Questionnaire............................................................47

4. Frequencies of Suicidal Planning and Attempts............................... 48

5. Frequency of Suicidal Ideations............................................49

6. Frequency of Suicidal Threats...................................................

7. Means for the Five Factor Model Rating Form (FFMRF) .........................51

8. Cyberbullying and Subtype Prevalence Rates....................................52

9. Most Frequent Behavioral Responses to Cyberbullying Victimization by Gender.........53

10. Topics of Attacks made to or about Cyberbully Victims..........................54 


\section{LIST OF FIGURES}

1. The Relationship between Traditional Bullying, Cyberbullying, and Stalking Behaviors.....44 
Psychological Impact of Cyberbully Victimization among College Students

On October $16^{\text {th }}, 2006$, the parents of Megan Meier entered their daughter's bedroom to find their 13-year-old child hanging lifelessly in her closet (-Parents," 2007). To add to this tragedy, it was determined that Megan had received countless harassing messages about her worthlessness and urging her to end her life. On January $14^{\text {th }}, 2010,15$-year-old Phoebe Prince took her life as a result of being cyberbullied. After her death, classmates came forward to reveal that Phoebe had been incessantly harassed by text messages and posts on social networking sites (Johnson, 2010). As recently as September 22 $2^{\text {nd }}, 2010,18$-year-old Tyler Clementi jumped to his death from the George Washington Bridge after his roommate streamed video of him and another male over the Internet (Friedman, 2010). These are examples of tragic deaths that were related to cyberbullying. As a result of this growing problem, fifteen states have adopted or are in the process of adopting laws against cyberbullying (Hinduja \& Patchin, 2009).

Unfortunately, incidents like this are occurring more and more frequently in our society. With technology influencing every aspect of our lives, information is being spread with great ease and speed. As of 2008, 72.4\% of the U.S. population was documented Internet users (-Internet users,” 2009). Text messaging, video messaging, emails, instant messaging, social networking sites, blogs, and many other technological advances are facilitating the spread of information. While there are many benefits to these methods, such as the efficient transmission of knowledge, there is also a darker side emerging. Often the information that is being shared can be damaging, harassing, and malicious. This raises the issue of traditional methods of bullying moving into the technological realm. 


\section{Defining Traditional Bullying and Cyberbullying}

Traditional bullying was defined by Olweus (1993) as being exposed, repeatedly and over time to negative actions by one or more other people. Bullying can be direct, such as physically beating someone up, or indirect, which includes non-face-to-face methods like spreading rumors. This definition contains components that overlap with the definition of

cyberbullying (Figure 1). Furthermore, Dempsey and colleagues (2009) found relational, overt, and cyberbullying, based on victimization, were distinct constructs from one another as a result of factor analysis techniques of their sample. Cyberbullying is a repeated, intentional act done with the purpose of harming another person through technologies such as email, cell phone messaging, social networking web sites, chat rooms, and instant messaging (Beran \& Li, 2005; Bhat, 2008; Campbell, 2005; as cited in Mason, 2008; Patchin \& Hinduja, 2006). It can be perpetrated by a single individual or a group of people (Smith et al., 2008). Unlike traditional bullying, cyberbullying does not require a face-to-face confrontation or a physical location to convene and can be completely anonymous (Dehue, Bolman, \& Völlink, 2008; Mason, 2008).

Cyberbullying not only differs from traditional bullying, but it is also a separate phenomenon from stalking. Stalking is defined as the "unwelcome, repetitive, and intrusive harassing and/or threatening behavior directed toward a specific individual" (Westrup \& Fremouw, 1998, p. 255). The direct threat involved in stalking is a key component to defining these behaviors and it differentiates stalking from harassment, which does not include a threat. Stalking is typically viewed as an extreme form of direct (or traditional, face-to-face) bullying. A new variation of this behavior, known as cyberstalking, is also emerging. Similar to the relation between stalking and traditional bullying, cyberstalking is an extreme form of cyberbullying (see Figure 1). It has been defined as the use of technological mechanisms to 
"bully, threaten, harass, and intimidate a victim," as well as a form of "emotional terrorism" (Maxwell, 2001, p. 6). While these two categories are related, the extreme nature of cyberstalking is beyond the scope of this research study.

Most studies have defined cyberbullying in similar ways with only slight variations. For example, Mason (2008) categorized cyberbullying as a form of psychological cruelty" that included a new form of bullying that is simply a more -eovert form of verbal and written [traditional] bullying” (p. 323). Also, some researchers do not include the repetition component when defining cyberbullying (e.g. Privitera \& Campbell, 2009; Raskauskas \& Stoltz, 2007; Slonje \& Smith, 2008). However, to leave this aspect out over-generalizes cyberbullying by including incidents that happened only once or by chance. Some researchers also include the component of a power differential between the victim and the perpetrator of cyberbullying (Hinduja \& Patchin, 2007; Mason, 2008; Privitera \& Campbell, 2009). A power imbalance could be based on actual power criteria, such as physical strength, body build, age, or on technological ability (Vandebosch, 2008). However, we do not believe the power differential is a necessary element to the definition of cyberbullying due to the anonymity and security offered in this format. The anonymity provided by technology can actually help create a power advantage, where cyberbullying can be a way for smaller, less powerful victims of traditional bullying to stand up or get revenge on their more powerful aggressor(s) (Campbell, 2005; Dehue, Bolman, \& Völlink, 2008; Li, 2007a; Ybarra \& Mitchell, 2004). For example, a young teen can spread damaging information over the Internet about an older and stronger person with impunity due to the inscrutability.

Li (2007a) outlined seven different forms of cyberbullying that constitute this new phenomenon. The seven categories of cyberbullying are: flaming, online harassment, 
cyberstalking, denigration, masquerading, outing, and exclusion. Flaming involves the electronic transmission of angry, rude, and vulgar messages, whereas online harassment is the repeated sending of messages. Cyberstalking entails threats of harm or intimidation.

Denigration (put-downs) is sending cruel, and possibly untrue, information about a person to others. Pretending to be someone else and sharing information to damage a person's reputation or relationships is classified as masquerading. Outing is the sharing of sensitive or private information about a person to others. Finally, exclusion involves maliciously leaving someone out of a group online.

(In this study, we do not incorporate exclusion in our definition of cyberbullying because of its subjectivity. For example, while an individual may have felt as if he or she was being left out of an online group, this may not have been done intentionally by other members of the group. Also, it is not possible for an individual to accurately know how often he or she was purposely left out of an online group. We also combined flaming, online harassment, denigration and outing into one category of harassment due to the similarities of these four types and the overlap between them.)

\section{Prevalence Rates of Cyberbullying}

Since various studies define cyberbullying in slightly different ways, diverse prevalence rates are reported. Factors such as sample size and the age group studied can also influence the stated prevalence rates of cyberbullying. As a general estimate, the Second Youth Internet Safety Survey, a national survey collected in $2004(n=1,500)$, reported the overall prevalence rate for Internet users involved with online aggression between the ages of 10 and 17 to be $9 \%$ (Ybarra, Mitchell, Wolak, \& Finkelhor, 2006). Notably, this was a 50\% increase in the prevalence of cyberbullying from when the first Youth Internet Safety Survey that was 
administered in 2000 (Ybarra \& Mitchell, 2004). Within smaller and more specific studies the rates vary.

Dehue, Bolman, and Völlink (2008) examined experiences with cyberbullying in the Netherlands with a sample of final-year pupils of primary schools and first-year pupils of secondary schools. Using this sample of children $(n=1,211)$ and a self-developed questionnaire to assess victimization and perpetration of cyberbullying, results indicated that $23 \%$ of students had been victims of cyberbullying, while $16 \%$ had engaged in bullying others via the Internet and/or text messaging.

At the middle school level, Canadian students completed a self-report questionnaire regarding their experiences with cyberbullying (Li, 2007a). They found that $24.9 \%$ of the sample $(n=177)$ were victims of cyberbullying and $14.5 \%$ were cyberbullies. A sample of seventh grade students $(n=461)$ in both Canada and China completed the same questionnaire (Li, 2007b). Results showed that one in three students had been victims of cyberbullying and one in five students were cyberbullies. Furthermore, of those who had been victims of cyberbullying, over $40 \%$ had been cyberbullied more than three times, and two out of three cyberbullies had harassed others four or more times. These results exemplify how frequently cyberbullying is occurring and being experienced by middle school-age children. An additional research study conducted by Beran and Li (2005) used a sample of Canadian middle school students $(n=432)$ to examine the prevalence of cyberharassment. In this study, the term cyberharassment was synonymous to cyberbullying. In this sample, $21 \%$ of students had been frequently cyberharassed and 3\% disclosed cyberharassing others.

Surveys including both middle school and high school children have examined the prevalence of cyberbullying. Two studies were conducted by Smith and colleagues (2008) using 
a sample of children from the United States, ages 11 to 16 . The first study included 92 students; the second study had 533 students and was conducted to assess the generalizability of the results from the first study. Study One found that $6.6 \%$ of students had been bullied $\rightarrow$ ften" (two or three times a month) and $15.6 \%$ had experienced cyberbullying at least once or twice. Study Two revealed similar rates, as well as $11.1 \%$ of the sample admitted to cyberbullying someone else within the past year (Smith et al., 2008). A population study of Finland youth, ages 13 to 16 $(n=2,215)$, reported a prevalence rate of $4.8 \%$ cyberbully victimization within the last six months (Sourander et al., 2010). Hinduja and Patchin (2008) also analyzed the prevalence of cyberbullying among American respondents up to 17 years old $(n=384) .30 \%$ of respondents reported being victims of cyberbullying and $11 \%$ admitted to cyberbullying others. In a similar study of 13 to 18 year old American adolescents $(n=84), 48.8 \%$ reported being cyberbully victims, and $21.4 \%$ of the sample admitted to being cyberbullies (Raskauskas \& Stoltz, 2007). Lastly, Slonje and Smith (2008) assessed experiences with cyberbullying of 360 Swedish students, ages 12 to 20 . The overall cyberbullying victimization rate for the entire sample was $11.7 \%$, and $10.3 \%$ of pupils endorsed cyberbullying others.

To date, only one study has investigated prevalence rates of cyberbullying among college students. Kraft and Wang (2010) examined cyberbullying, as well as cyberstalking, among students at a college in the United States. This study reported prevalence rates of $10 \%$ for cyberbullying victims and 9\% for cyberstalking victims among a sample of 471 participants.

Unfortunately, there is a great shortage of research conducted regarding cyberbullying with a college sample. This is a great oversight, especially considering the reliance on technology for college students. At that point in their lives, many students find themselves separated from their family and friends for the first time, and as a result they utilize tools such as 
cellular phones, email, and social networking websites in order to stay connected. With the use of technology also comes the increased potential for individuals to become victims or perpetrators of cyberbullying. The likelihood of being a victim and/or perpetrator of cyberbullying has been found to be positively correlated with the amount of time spent on the Internet, as well as computer proficiency (e.g. Li, 2007a, 2007b; Patchin \& Hinduja, 2006). Ybarra \& Mitchell (2004) also reasoned that with older adolescents more independence and privacy are granted, and as a result, there is a greater likelihood that they will be involved in cyberbullying. This logic can be applied to young adults in college as well.

While cyberbullying in college has not been extensively researched, Privitera and Campbell (2009) examined the prevalence of cyberbullying in the workplace. Using randomly selected members of the Australian Manufacturing Workers' Union, prevalence and methods of cyberbullying for male employees was investigated. The results indicated $10.7 \%$ of the sample of employees $(n=103)$ had been cyberbullied. Information on perpetration of cyberbullying was not reported. These results further support the idea that the form of traditional bullying is changing with technological advancements, not only in school settings, but beyond.

In comparison to cyberbullying, prevalence rates of traditional bullying have been found to range between $4.1 \%$ for girls and $5.6 \%$ for boys, and reach has high as $32.3 \%$ for girls and $36.3 \%$ for boys (Due et al., 2009). This comprehensive study was based on a sample of 162,305 students' ages 11, 13, and 15 years old, from 35 countries in Europe and North America. This survey was issued in the 2001-2002 school year to 5998 different schools. Prevalence rates of cyberbully victimization were up to approximately $40 \%$ in some studies, but generally reflected a similar prevalence rate to the higher end rates of traditional bullying reported in this one comprehensive study. 


\section{Theories of Bullying and Cyberbullying}

Due to the novelty of cyberbullying, there are few specific theories to explain this phenomenon. However, there are numerous theories of traditional bullying that can be generalized to shed light on the new trend of cyberbullying.

Rigby (2003) summarized four different theoretical perspectives on bullying. A developmental theory states that physical bullying is fairly common in early childhood as children begin to assert themselves and determine their social dominance. However, physical bullying turns to more indirect and discrete methods as children age and socially develop.

Attribution to individual differences is the second theory and takes the perspective that different individual characteristics cause people to bully, such as high levels of aggression and low levels of empathy. Also, different individual characteristics can increase someone's likelihood of being a victim. A third theory regarding bullying is that bullying is a sociocultural phenomenon. This theory explains bullying as a result of different social groups with different levels of power interacting with one another. Gender, racial/ethnic groups, and social class are the three most salient social divides that can exist and promote bullying. Bullying that occurs as a reaction to group and peer pressure within the school is a fourth theory used to explain bullying. Within the context of schools, certain groups naturally form (jocks, populars, brains, etc.), and as a result there is an -ut group" of non-members for whom to bully. The motive in this perspective can vary from a conceived prejudice to the mere desire to have fun at the expense of others.

Specifically in regards to cyberbullying, the developmental theory could help explain the turn to indirect forms of bullying especially in middle school and high school-age children. Attribution to individual differences could also carry over and play a role in why some individuals chose to cyberbully and others do not. Like traditional bullying, cyberbullying could also be the result of 
group membership or peer pressures encountered within schools flowing over into the cyberworld.

The theory of attributing individual factors to explain traditional bullying, as well as how they could be applied to cyberbullying was elaborated by Bhat (2008). More specifically, impulsivity may be a key component in cyberbullying others. Cyberbullying could occur as the result of making a hasty decision, not considering the consequences of one's actions, or acting out in retaliation against someone. For example, sending or posting sexually explicit messages or photographs as the result of an ended relationship could be an incident of cyberbullying that was committed on impulse due to wounded pride and hurt feelings. Therefore, a theory incorporating impulsivity is extremely applicable to cyberbullying, according to Bhat (2008).

Sutton, Smith, and Swettenham (1999) inspected the theory of mind perspective on traditional bullying and took a new position on the social skills deficit model. Traditionally, bullies have been viewed as —pwerful but oafish" [people] with little understanding of others" (Sutton et al., 1999, p. 117). However, this article recognizes bullies as actually possessing social skills and the ability to understand others in order to manipulate, harm, and inflict suffering on them, all while avoiding detection. Most bullying requires some degree of understanding, the capability to —rmipulate the mind of others," and to avoid detection (Sutton et al., 1999, p. 121). This theory of mind perspective is extremely applicable to the method of cyberbullying. For example, forethought and planning goes into choosing to masquerade as someone else. Additionally, outing someone by spreading damaging information takes a component of manipulation as well as strategy to inflict the most severe degree of harm on the victim. 
More specific to cyberbullying, Hinduja and Patchin (2007) attempted to apply the general strain theory to victims of cyberbullying to better understand the emotional and behavioral consequences experienced. While this study demonstrated victims of cyberbullying experienced more emotional and psychological harm, as well as showed an increased association between victimization and offline deviant behavior, general strain theory does not necessarily explain these consequences of cyberbully victimization adequately. The explanation that cyberbullying is a potent form of strain that may be involved in school problems and delinquent behavior offline" seems to be a stretch, as there could be numerous other factors motivating the offline behavioral problems of cyberbully victims (e.g. personality characteristics, peer influence, desire for attention, etc.) (Hinduja \& Patchin, 2007, p. 89).

Mason (2008) elaborated on three distinct psychological explanations for cyberbullying. The disinhibition effect capitalizes on the anonymity offered by technologies, specifically the Internet. The anonymity allows individuals to lower restraints and behave in ways they might not if their identity was clearly known. A virtual identity" begins to form, which is less inhibited than the individual's actual identity, as described by Joinson (1998) (as cited in Mason, 2008). Supporting this, Gross theorizes that the anonymity of the Internet allows adolescents an opportunity to experiment with their identity through role playing, persona creation, and fantasy (as cited in Mason, 2008). Also, there are often very few consequences encountered for cyberbulliers and their actions. Next, the identity transition from private to social self explains cyberbullying as occurring due to the anonymity offered by the Internet causing individuals to act in regards to their social group identities, rather than their own personal identities (Mason, 2008, p. 329). This leads an individual to respond or behave in a manner that is consistent with a social group they identify (or wish to identify) with. The anonymity offered by the Internet, in 
addition to the anonymity provided by group membership allows individuals to completely relinquish their personal identity, as well as their concern for personal responsibility.

The last theory Mason (2008) applied to cyberbullying is a lack of adult interaction, which includes both poor parental monitoring and poor relationships between parents and children. Poor parental monitoring simply involves parents not having guidelines, rules, or monitoring of children and their use of technology. Poor relationships between parents and children are exacerbated by a divide in technological knowledge and confidence. This disconnect can influence parent-child communications, emotional bonds, and trust, which contribute to a child's likelihood of being involved with cyberbullying (Mason, 2008). Particularly, those who cyberbully others are more likely to have a negative parent-child relationship than non-cyberbullies (Ybarra \& Mitchell, 2004). Through a comprehensive survey of 1,501 regular Internet users in the United States, ages 10 to 17, negative parent-child relationships were assessed based on three categories: emotional closeness, general parental monitoring, and discipline. In addition to Internet use and psychosocial challenge, poor parentchild relationships were the only characteristics cyberbullies shared with one another.

\section{Impact of Cyberbully Victimization}

Victims of traditional bullying are often negatively impacted as a result of being victimized. For example, some research has shown victims tend to be more isolated and less accepted by their peers, as well as manifest more internalized psychosocial behaviors, such as depression, anxiety, and being quiet or withdrawn (as cited in Conners-Burrow, Johnson, Whiteside-Mansell, McKelvey, \& Gargus, 2009). Similarly, it seems very likely that victims of cyberbullying would also be negatively impacted. 
Research has shown that victims of cyberbullying respond in a variety of ways, and at the very least, most showed an increase in emotional distress (Ybarra \& Mitchell, 2004). Typical responses to online victimization were found to include frustration, anger, and sadness. Additionally, the more cyberbullying that was experienced, the more offline problems victims exhibited (Hinduja \& Patchin, 2007). Beran and Li (2005) identified being angry and crying as the most frequent reactions to cyberbullying. Also being sad, hurt, anxious, embarrassed, afraid, and blaming oneself were common emotional responses to victimization (Beran \& Li, 2005). Finkelhor, Mitchell and Wolak (2000) found that one third (32\%) of cyberbully victims experienced at least one symptom of stress, 31\% were upset, 19\% were afraid, and 18\% were embarrassed as a result of being cyberbullied.

Canadian cyberbully victims in $7^{\text {th }}$ through $9^{\text {th }}$ grade reported poor concentration, low school achievement, and absenteeism as common reactions (Beran \& Li, 2005). Consciously avoiding the Internet, dwelling on the harassment, feeling jumpy or irritable, and losing interest in things were also found to be common experiences among cyberbullying victims. Adolescent victims were more likely to have behavior problems, consume alcohol, smoke, and have low school commitment than adolescent non-victims (Mason, 2008). A population-based study of cyberbullying in adolescents from Finland found victims experienced emotional and peer problems, headaches, recurrent abdominal pain, problems sleeping, and not feeling safe at school compared to non-victims (Sourander et al., 2010). An American-based study found victims of cyberbullying had significantly lower self-esteem than other middle school students that had no experience with cyberbullying (Patchin \& Hinduja, 2010). Cyberbullying experienced in the workplace was typically associated with negative physical health, negative emotional wellbeing, 
impacted social and family relationships, as well as a reduction in staff morale, commitment, job satisfaction, and a breakdown of work relationships (Privitera \& Campbell, 2009).

Ybarra (2004) found that victims of cyberbullying, ages 10 through 17, endorsed more depressive symptoms than non-victims. Furthermore, Fauman (2008) identified common psychological consequences related to cyberbullying victimization as depression, anxiety, suicidal ideation, poor concentration, as well as a sense of helplessness and low self-esteem. This has been expanded by Thomas (2006), and anxiety, school phobia, depression, lowered selfesteem, emotional distress, and suicide were acknowledged as potential results of being a victim of cyberbullying among adolescents, ages 13 through 18. Raskauskas and Stoltz (2007) recognized that extreme cases of cyberbully victimization have been linked to adolescent suicide.

Empirically, Hinduja and Patchin (2010) investigated the relation between suicidal behaviors (ideation, attempts/experiences) among traditional and cyberbully victims and perpetrators. Their research revealed a link between youth who experienced traditional or cyberbullying, as either perpetrators or victims, and more suicidal thoughts and an increased likelihood of attempting suicide compared to a control group. This finding was even more strongly related for victims, rather than perpetrators, of both forms of bullying.

Slonje and Smith (2008) examined which specific methods of cyberbullying had the greatest impact on victims. Overall bullying via picture/video messaging was perceived as having a greater impact than traditional bullying and other forms of cyberbullying. All other forms of cyberbullying were reported as having an equivocal impact on its victims. Regardless of the form of technology used to cyberbully, the impact on victims is substantial. Some factors that can escalate the severity of the impact are the increased difficulty to escape the 
cyberbullying, as well as the countless bystanders that can view this private information due to the ease of electronic transmission (Slonje \& Smith, 2008; Campbell, 2005; Bhat, 2008).

\section{Methods for Coping with Cyberbully Victimization}

Coping strategies to deal with these negative consequences of cyberbullying varied across empirical studies. For example, some victims removed themselves from the particular website, stayed offline for a period of time, talked about their experience with a friend, and a few informed a teacher or an adult about what they experienced (Hinduja \& Patchin, 2007). Telling someone and blocking/avoiding the technological device were viewed as the best methods, although doing nothing/ignoring, blocking one's identity, keeping a record of offensive emails/texts, reporting the occurrence to police/authorities, contacting the service provider, asking the perpetrator to stop, and fighting back were also identified as methods for dealing with cyberbully victimization in 11 through 16 year olds in England (Smith et al., 2008). In addition, pretending to ignore it, really ignore it, deleting all the bullier's messages, and bullying the bully were additional strategies identified by a sample $(n=1,211)$ of primary school children and firstyear pupils of secondary schools in the Netherlands (Dehue, Bolman, \& Völlink, 2008).

Similarly, victims of serious traditional bullying (-serious" based on duration of bully victimization and frequency) were found to: ignore the bully, tell them to stop, ask for help from an adult, fight back, cry, ask friends for help, or run away (Smith, Shu, \& Madsen, 2001). These reactions were found to vary in prevalence based on the child's age $(10,11,12$, or 13-14 years old).

It is evident that victims of cyberbullying negatively react and cope with the experience in a variety of ways. To date, the majority of research has been done using school-age children (elementary, middle, and/or high school) as well as adults in the work force, with only one study 
examining college students. Research is necessary to identify the prevalence of cyberbullying in a college sample, how this age group experiences victimization, and what coping strategies are utilized. Cyberbullying is especially relevant for this age group since they are typically just out of high school (where cyberbullying is still prevalent) and they are more independent from parental influences. There also needs to be more research focusing on cyberbullying in the United States as much of the research has been conducted internationally.

\section{Purpose}

The purpose of this study was to examine a) the prevalence, b) the psychological impact, and c) the coping strategies of college student victims of cyberbullying. The victims were selfidentified by an anonymous questionnaire and compared to a control group of non-victims.

1. The first purpose of the study was to examine the prevalence rates of cyberbullying among college students. This was exploratory due to the lack of previous research with this age group. An Internet Experiences Questionnaire (see Appendix A) was administered to 856 undergraduate college students via Sona. The results were reported by overall rate of cyberbully victimization, overall rate of victimization by gender, as well as the type of cyberbullying (e.g. picture/video messaging, masquerading, etc.).

2. The second purpose of the study was to examine the psychological and behavioral impact of cyberbully victimization. It was hypothesized that the cyberbully victims would report experiencing more negative emotions, more psychological symptoms, and more negative behavioral changes as a result of their victimization compared to controls. The Internet Experiences Questionnaire (IEQ) and the Symptoms Checklist-90-Revised (SCL-90-R; see Appendix B) were administered to assess the impact of cyberbully victimization. 
3. The third purpose of the study was to conduct the following exploratory analyses:

a. The first analysis was to examine potential differences of suicidal behaviors between cyberbully victims and controls. The frequency of suicidal behaviors from the Suicidal Behaviors Questionnaire-Revised (see Appendix C) was examined to determine if there were differences between participants who have been victims of cyberbullying and those who have not.

b. The second analysis was to examine potential differences in personality characteristics of victims as compared to controls based on the Five Factor Model Rating Form (Widiger, 2003; see Appendix D). This was investigated to determine if there were personality profiles of cyberbully victims that could increase the likelihood of certain people being victimized, as postulated by Rigby‘s theory of attribution to individual differences (2003).

c. A third analysis was to examine impact differences based on the form of cyberbullying. The difference between the types of cyberbullying experienced on the victim impact was investigated. Specifically, the impact experienced by victims of masquerading was analyzed to determine if that form was more damaging than other forms of cyberbullying, due to the elevated degree of manipulation and deceit involved in masquerading. Also, the impact of picture/video messaging was investigated to better understand if this type of cyberbullying has a greater impact on its victims as found by Slonje and Smith (2008). Lastly, the impact of Internet bullying was also investigated due to prevalence.

4. The fourth purpose of the study was to determine what coping strategies were utilized by cyberbullying victims based on the IEQ. 
5. The final purpose of the study was to determine if there were gender differences in the prevalence, impact, and coping strategies of victims by examining male versus female cyberbully victims. An analysis of gender differences in the psychological impact, behavioral changes, and negative reactions experienced by cyberbully victims was investigated and compared to controls (when appropriate) in a 2 × 2 design.

\section{Participants}

\section{Methods}

A sample of 856 participants $(69.4 \%$ female, $30.6 \%$ male) completed this study. The infrequency validity scale adopted from the Zuckerman-Kuhlman Personality Questionnaire (Zuckerman, 2002) was utilized to select out participants who likely did not attend to item content when responding to the measures in this study (using a cut-off criterion of 4 and greater). Additionally, participants were eliminated from subsequent analyses if they completed the study in 10 minutes or less. Six participants were excluded based on the ten minute time criteria, 48 participants were excluded based on the Zuckerman-Kuhlman infrequency validity scale, and an additional three participants were eliminated due to selecting -decline to answer" for every question. Given these exclusionary criteria, a sample of 799 participants $(71.6 \%$ female, $28.4 \%$ male) remained. The age range was $18-24$ and the mean age was $20.01(S D=2.41)$. Of these participants, $21.2 \%$ were college freshman, $40.7 \%$ were sophomores, $22.0 \%$ were juniors, and $13.5 \%$ were college seniors. Additionally, $2.6 \%$ of participants identified as graduate students or -ther".

Of this sample, 734 self-identified as white or Caucasian, 19 participants self-identified as African American, 13 participants identified as Latino or Hispanic, 13 participants identified as Asian, and two participants identified as Native American. A total of 15 participants chose the -ther" option to represent their ethnicity and three participants declined to answer this question. 
The racial composition of this sample is typical for the mid-Atlantic university from which it was drawn. All participants were from undergraduate psychology classes and received extra credit for participating. The study was approved by the University`s Institutional Review Board.

Participants were defined as victims if they meet a dual-criteria by admitting to having experienced cyberbullying behaviors at least four times or more and answering yes ${ }^{6}$ to a question specifically about being a victim of cyberbullying (i.e. Since being at WVU, have you been a victim of cyberbullying'). Controls endorsed never experiencing cyberbullying or experiencing it three times or less and answered no' to a question regarding being a victim of cyberbullying. A cut-off value of four or more experiences of cyberbully victimization was determined by preliminary analyses that indicated individuals experiencing two or three experiences of cyberbullying were not significantly different than control participants who never or only once experienced cyberbully victimization.

Given that the primary purpose of this study was to assess characteristics of victims of cyberbullying, the sample of 799 participants was further divided into an experimental and control group. A control group $(n=69)$ was matched to the experimental group $(n=69)$ of cyberbully victims on participant characteristics of sex and age (Table 1). A total of 138 participants were included in all subsequent analyses. There were no significant differences in demographic characteristics between matched and non-matched control participants.

\section{Measures}

Demographic Questionnaire. Participants responded to demographic questions regarding age, ethnicity, sex, martial status, class status (e.g., freshman, sophomore, etc.), GPA, mental health services history, and Internet usage. 
Internet Experiences Questionnaire (IEQ). This questionnaire was developed by the researcher for the purpose of this study. Because of the novel and eclectic nature of this measure, there was no previously established validity or reliability. It combined aspects from several questionnaires previously developed and utilized in different research studies (Raskauskas \& Stoltz, 2007; Smith, Mahdavi, Carvalho, \& Tippett, 2006; Willard, 2007; Beran \& Li, 2005). The IEQ is a 47-item questionnaire with sections addressing: perpetrators of cyberbullying, traditional bullying victims, cyberbullying victimization separated by different types of cyberbullying (text messaging, Internet, picture/video messaging, phone calls, and masquerading), general cyberbullying experiences, and impact and coping methods.

Questions on the IEQ were answered in a variety of ways. Many were open-ended questions that allowed participants to fill in their own responses (e.g. If you were a victim of cyberbullying, how did you get the harassment to stop?'). This questionnaire also contained multiple-choice questions, which allowed for only one answer to be selected (e.g. 'Since you've been at WVU, have you been a victim of cyberbullying?' Yes or No), as well as multiple-choice questions that allowed for several answers to be selected (e.g. 'If you have been cyberbullied in any way, what sorts of comments/remarks were made? Please check all that apply: appearance, race, sexual orientation, etc. ').

Symptom Checklist-90-Revised (SCL-90-R). The SCL-90-R is a commonly used measure to aid in diagnosis, treatment planning, and treatment effectiveness. The SCL-90-R is a 90-item self-report survey that assesses nine symptoms of psychopathology (Somatization, Obsessive Compulsive, Interpersonal Sensitivity, Depression, Anxiety, Hostility, Phobic Anxiety, Paranoid Ideation, and Psychoticism). Three global distress indexes are also calculated (Global Severity Index, Positive Symptom Distress Index, and Positive Symptom Total). All 
responses are measured on a five-point Likert scale $(0=$ not at all, $1=$ a little bit, $2=$ moderately, 3 = quite a bit, and 4 = extremely) to assess how frequently the participant has experienced the symptoms in the last week. The SCL-90-R has been well-validated with good internal consistency and test-retest reliability (Derogatis, 1994). SCL-90-R was normed on adolescent (ages 19 and younger) and adult psychiatric inpatients (ages 20 and older), as well as community nonpatient adults and adolescents. The norms are based on normalized $t$ scores, due to the fact the raw scores are not normally distributed (Todd, Deane, \& McKenna, 1997). Cronbach's alphas for the nine subscales of the SCL-90-R ranged from .84 to .98 .

Suicidal Behaviors Questionnaire-Revised (SBQ-R). The SBQ assesses the types of suicidal ideations and behaviors participants have engaged in with the use of Likert-type scales (Linehan \& Nielsen, 1981). Different lengths and variations of the measure are available. This study utilized the SBQ-R with four items assessing suicide plans/attempts, suicidal ideation, suicidal threats, and likelihood of future suicide. Only one answer is selected for each item, but the selection choices and number of choices vary based on the item (please refer to Appendix C). This shortened version was originally used and adapted by Cole (1988). This measure has been studied with a variety of populations, such as psychiatric outpatients and college students. It has been shown to have strong test-retest reliability $(\mathrm{r}=.95)$, as well as concurrent validity with the Scale for Suicide Ideation, Linehan Reasons for Living Inventory, and self-harm measures in the Diagnostic Interview for Borderlines (as cited in Brown, 2001). Cronbach's alpha for the fouritems of the SBQ with this sample was .83.

Five Factor Model Rating Form (FFMRF). The FFMRF is a 30-item self-report survey assessing personality traits (Widiger, 2003). All responses are measured on a five-point Likert scale $(5=$ extremely high, $4=$ high, $3=$ neither high nor low, $2=$ low, $1=$ extremely 
low). The questions are numerically grouped into five sections of six questions each. Each section assesses a particular continuum of personality traits. The five continuums are fneuroticism versus emotional stability," -xtraversion versus introversion," -penness versus closedness to one‘s own experience," agreeableness versus antagonism," and eonscientiousness versus undependability." An identifying term for each end of these continuums, along with two to four adjectives to describe each, are provided for all the items (Widiger \& Lowe, 2007).

The five personality traits that were specifically measured are neuroticism, extraversion, openness to new experiences, agreeableness, and conscientiousness. A separate total was calculated for each of these five sections by adding the ratings. Higher subscale scores indicated a greater likelihood that the individual exhibited that personality trait. Lower subscale scores indicated the individual possessed and displayed more traits indicative of the opposite personality trait, or the other end of the continuum, for that subscale.

Using these five factors to assess personality characteristics has been widely established as acceptable practice. Specifically, assessing these five factor personality traits using a rating form with bipolar adjective choices has been empirically supported and well-validated. Typical intraclass correlations between raters ranged from .30 to .65 and the correlations between mean peer ratings and self-reports was .25 to .62 (McCrae \& Costa, 1987). These results were comparable to those from the NEO (Neuroticism-Extroversion-Openness) Personality Inventory. For neuroticism, extraversion, openness, agreeableness, conscientiousness, cronbach ‘s alpha values were $.79, .73, .51, .62, .82$, respectively. 


\section{Procedures}

After exclusionary criteria were implemented, 799 participants were administered all of the self-report measures via West Virginia University‘s online Sona system. Sona is a webbased survey management system specifically designed to facilitate research conducted at universities. On the Sona website, the study was entitled Internet Experiences of College Students," in an effort to avoid a selection effect of participants of victims or perpetrators of cyberbullying. Participants who were currently taking an undergraduate psychology course could choose to receive extra credit for taking part in this study. All respondents first read an informed consent form, which detailed the purpose of the study. After reading this information, if participants chose to take part in this study they had to select the IAgree" option before being allowed to continue. They were then directed to the anonymous survey. Participants completed a demographic questionnaire, IEQ, SCL-90-R, SBQ-R, and the FFMRF. Participants could decline to answer any question and they could withdraw their participation at any time. Upon completion of the study, participants were debriefed regarding their participation and provided with contact information for psychological services available to them. Additionally, due to the nature of the SBQ-R, participants were provided these same resources for psychological services immediately following the administration of this questionnaire, as well. The average time it took to complete the study for all participants was 40.18 minutes. The mean time for victims was 40.88 minutes $(S D=15.12)$ and 38.28 minutes for control participants $(S D=13.39)$. Based on an independent samples t-test, there was not a significant difference in the amount of time it took victims compared to controls to complete the study. 


\section{Data Analysis}

A power analysis was conducted to determine the appropriate number of participants necessary in order to find a moderate effect size in the data.

1. Prevalence was determined based on the dual-criteria perviously outlined and obtained from answers on the IEQ. Specifically, participants answered yes ${ }^{6}$ to the question Since being at WVU, have you been a victim of cyberbullying?" and endorsed having personally experienced at least one form of cyberbullying victimization (e.g., text messaging, picture/video messaging, masquerading, etc.) on four or more occasions. Prevalence was reported as a percentage of the total sample. These were between-group analyses as it compares victims to non-victims of the sample. (Purpose 1)

2. The psychological impact was examined by comparing the victims of cyberbullying to the control group (matched for age and gender) and examining the different outcomes of the dependent measures (IEQ, SCL-90-R) with Bonferroni correction. This was a between-group analysis. (Purpose 2)

3. Exploratory analyses were conducted to investigate the potential relation between multiple variables. (Purpose 3)

a. Differences in the frequency of suicidal behaviors, as addressed on the Suicidal Behaviors Questionnaire-Revised (SBQ-R), between victims and controls were examined using ANOVAs, chi-squared goodness-of-fit analyses, and frequencies.

b. Personality differences were examined by comparing victims of cyberbullying to controls using the FFMRF and accounting for Bonferroni correction. In addition, a logistic regression was conducted to analyze specific personality characteristics that might increase the likelihood or predict being a victim of cyberbullying. 
c. Exploratory analyses of the victim impact by type of cyberbullying (masquerading, Internet, video/picture messaging) were examined by analyzing the primary outcome measure of the SCL-90-R with the use of ANOVAs.

4. Coping strategies were tabulated based on IEQ reports and reported in frequencies. (Purpose 4)

5. Gender differences in prevalence, impact, and coping strategies among cyberbully victims were analyzed using t-tests, ANOVA, and MANOVAs, when appropriate (Purpose 5)

6. Effect sizes of all relevant findings were reported.

\section{Results}

All analyses were conducted using PASW Statistics 18.

\section{Prevalence of Cyberbully Victimization}

The sample of 799 participants was comprised of 572 female $(71.6 \%)$ and 227 male (28.4\%) participants. Out of this sample, $69(8.6 \%)$ participants met the dual-criteria to be classified as cyberbully victims; 50 female ( $8.7 \%$ of the entire female sample) and 19 male (8.4\% of the entire male sample). Please refer to Table 1 for additional demographic characteristics of the sample.

\section{Psychological Impact}

It was hypothesized that cyberbully victims would experience more negative reactions and psychological distress than control participants. To evaluate this hypothesis, a multivariate analysis of variance (MANOVA) was conducted with the subscales of the SCL-90-R as the dependent variable and found to be significant, $F(9,126)=3.35, p=.001$, partial $\eta^{2}=.193$. The results of 2 x 2 univariate ANOVAs were analyzed to identify significance on individual scales. 
A Bonferroni significance value of $p<.0055$ was used due to the exploratory nature of these analyses. Using this conservative significance criterion, there were significant differences between cyberbully victims and controls on four of the nine clinical subscales (Table 2). Specifically, victims were significantly elevated on depression, anxiety, phobic anxiety, and paranoid subscales. There was no main effect for gender, nor was there a significant interaction between gender and group on any of the SCL-90-R subscales.

Separate $2 \times 2$ univariate analyses of variance were conducted to assess the significance of the additional SCL-90-R additional scales (GSI = Global Severity Index; PST = Positive Symptom Total; PSDI = Positive Symptom Distress Index). A significance value of $p<.0167$ was used with Bonferroni corrections. There were significant findings for GSI, $F(1,134)=8.01$, $p=.005$, partial $\eta^{2}=.056$, and PST, $F(1,134)=9.51, p=.002$, partial $\eta^{2}=.066$. Victims of cyberbullying were higher on the GSI and PST scales than control participants. There was no significant main effect for the PSDI scale. There was no effect for gender or a gender-group interaction on any of these three additional scales.

Cyberbully victims answered questions on the IEQ describing the impact of the victimization directly. Control participants selected -decline to answer" for these questions because the questions were all prefaced with "If you were a victim of cyberbullying, how have you been impacted?" and then proceeded to list different reactions. Table 3 shows the frequencies of each reaction to cyberbullying as reported by victims only. Using frequently' as the descriptor, $46.2 \%$ of cyberbully victims felt frustrated, $40.9 \%$ admitted to feeling stressed, and $37.9 \%$ felt sad or hurt. 


\section{Exploratory Analyses}

Suicidal Propensities. Suicidal behaviors were explored for potential differences between cyberbully victims and control participants. Two-way independent ANOVAs were conducted, each with an item from the SBQ-R as the dependent variable. A MANOVA was not used due to violated assumptions required for that statistical procedure (e.g., multicollinearity issues). The interaction effect between participant gender and group was not statistically significant, nor was there a main effect for gender on the four ANOVAs. There was a significant difference between victims and controls in terms of suicidal plans/attempts, $F(1,135)=9.21, p=$ .003 , partial $\eta^{2}=.064$, as well as in frequency of ideation, $F(1,135)=5.24, p=.024$, partial $\eta^{2}=$ .037. Cyberbully victims were also significantly different from controls in making suicidal threats, $F(1,135)=4.79, p=.030$, partial $\eta^{2}=.034$. The likelihood of completing suicide in the future was a trend, but did not reach significance.

Victims endorsed attempting suicide (5.7\% of victims) more than matched control participants $(0.0 \%)$. Please see Table 4 . A chi-square test of goodness-of-fit indicated that the frequency of suicidal planning/attempts was significantly different between control participants and victims, $X^{2}(3, N=138)=9.09, p=.028$. Victims also endorsed more frequent suicidal ideations (10.1\% of victims, $0.0 \%$ of controls). See Table 5 . A chi-square test of goodness-of-fit was performed to determine whether the frequency of suicidal ideation was equal between cyberbully victims and controls. Frequency of suicidal ideation was also significantly different in this sample, $X^{2}(2, N=138)=7.38, p=.025$. Victims also admitted to conveying their suicidal intent to others more often (5.8\% of victims) than controls (1.4\% of controls). See Table 6 . Based on a chi-square analysis, there was no significant difference between victims and controls and their likelihood to express their suicidal intentions. 
An independent-samples t-test was conducted to compare overall suicidal behaviors (as measured by total scores calculated from the SBQ-R) between cyberbully victims and control participants. There was a significant difference in the total scores for overall suicidal behavior for cyberbully victims $(M=2.39, S D=3.52)$ and control $(M=1.00, S D=2.00)$ participants, $t(1)$ $=-2.85, p=.005$. There was no effect for gender and overall suicidal behaviors.

Personality Differences. To examine whether cyberbully victims had different personality characteristics, their responses on the Five Factor Model Rating Form (FFMRF) were examined. A MANOVA with the five personality scales as dependent variables was run. There was a significant main effect for cyberbully group, $F(5,130)=3.48, p=.006$, partial $\eta^{2}=.118$. There was no effect for participant gender or the interaction between group and gender. Using a significance cut-off value of $p<.01$ to account for Bonferroni corrections, none of the personality scales met the criteria for statistically significant results (Table 7). However, the personality characteristic of neuroticism was very close to meeting this conservative significance criterion $(p=.012)$, as cyberbully victims $(M=16.57, S D=4.56)$ scored higher in neuroticism than control participants $(M=14.70, S D=4.32)$.

One of the original purposes of this study was to use personality traits from the FFMRF to run a logistical regression to predict group membership (cyberbully victim versus control). However, due to outlier patterns of data for this measure, results of the logistic regression were not able to be interpreted accurately, and the above MANOVA results should be interpreted with caution, as well. Please refer to Appendix E to see the results of the logistic regression.

Impact Differences. Cyberbullying was separated into five distinct subtypes: text messaging, Internet, picture/video messaging, phone calls, and masquerading. Table 8 displays the prevalence rates for each subtype. Since cyberbully victimization via text messaging and 
phone calls were the most prevalent medias of victimization and constituted more than $80 \%$ of victimization, those results were primarily examined and explained above. Therefore, the impact of the least prevalent forms (Internet, video/picture messaging, and masquerading) were teased apart and analyzed. Internet victimization involves both incoming harassment (personal messages/emails sent to the recipient), as well as outgoing (information available for other people to access). Video/picture messaging and masquerading are typically outgoing, public forms of victimization. Analyzing the results of the SCL-90-R based on the type of victimization (Internet, video/picture messaging, masquerading) did not reveal any significant differences in psychological impact.

Interestingly, of the four victims of cyberbullying that admitted to attempting suicide, three were victims of masquerading. One was also a victim of text messaging and picture/video cyberbullying, and another participant was a victim of cyberbullying via phone calls, picture/video messaging, Internet, and text messaging in addition to masquerading. One participant that attempted suicide only endorsed being a victim of text message cyberbullying, but experienced this victimization 15 times or more by classmates, friends/former friends, exboyfriend/girlfriend, and unknown parties. The most frequent perpetrator was reported to be a friend or former friend, but one participant did not know or was uncertain of the perpetrators identity for all forms of victimization, which included masquerading and Internet cyberbullying.

\section{Coping Strategies}

On the IEQ, participants were allowed to choose multiple options of what behaviors they did as a result of being cyberbullied. The five most frequently endorsed behavioral responses to cyberbully victimization by gender are shown in Table 9. Male and female cyberbully victims responded in similar manners and shared four out of five of the more frequent behavioral 
responses: told someone, avoided friends or peers, got revenge, and stopped going to events. The only difference was females were more likely to avoid the Internet/cell phones and males were more likely to drink alcohol/use illegal drugs.

They also responded to an open-ended question asking How did you cope with the experience [of being cyberbullied]?" The most common responses to this question regarding coping with victimization were: talked to someone (friend, family, significant other, etc.), ignored it, blocked contact, and got revenge. Some unique reactions included prayed," made certain it never happened again," "sought professional help," and moved."

Regarding how the individual got the cyberbullying to stop, participants responded to another open-ended question. Common responses were: ignored it, blocked person or changed phone number, reported it (police, residential authorities, campus police), and confronted the person doing it. Less frequent methods included: resolved the fight and confusion," moved," hit," and talked back." A total of seven participants indicated that the cyberbully victimization was ongoing.

\section{Additional Characteristics of Cyberbully Victimization Experiences}

Since very little is known about cyberbullying among college-age individuals, one of the main purposes of the IEQ was to gather exploratory data to improve understanding of the experience and guide future research. Participants were asked to select all of the applicable choices regarding the types of comments the perpetrator made to or about the victim (Table 10). Attacks about the victim's self-worth (e.g., you're worthless") were most common for males and females, but females second most common topic of attack was regarding sexual activity (e.g., -slut") and for males it was sexual orientation (e.g., -gay"). The third most prevalent topic of attack for both males and females was appearance (e.g., tgly"). 
Participants were given the opportunity to answer the open-ended question "If you have been a victim of cyberbullying, what was the reason someone did this to you?" The five most commonly reported explanations or motives were: jealously, dislike/hatred, anger, revenge, or the victim did not know what the perpetrator's motive was.

When asked If you were a victim of cyberbullying, how did it impact you?" participants had an opportunity to use their own words to describe the impact cyberbullying had on them. While some participants reported the cyberbullying did not bother them (approximately 12 participants), others voiced particularly poignant reactions to their victimization. For example, $\Psi$ had to seek professional help because I was depressed. I was put on Zoloft" and It was awful. I had to move out of my dorm room freshman year and made my freshman year experience including grades and quality of life miserable. I almost left this university because of it. I also had to see a counselor because of the development of depression" were two examples of responses that highlight the severe impact cyberbullying can have on victims. The most frequent free responses were: feeling hurt, upset, angry, bad about self/depressed, awkward or embarrassed, and annoyed. Additionally, some participants reported feeling unsafe and scared, losing friends, drinking alcohol and sleeping more, and believing the negative things that were said. The participants ' free response to this open-ended question helped better understand and describe the true impact cyberbullying victimization had, as well as illustrated the extensive range of impacts on victims.

\section{Discussion}

The baseline prevalence rate for cyberbully victimization in this sample was $8.6 \%$. This prevalence rate is comparable to the $10 \%$ found in one other study examining cyberbullying among college students (Kraft \& Wang, 2010). Additionally, there were nearly equivalent 
prevalence rates of victimization among males and females in this sample $(8.4 \%$ and $8.7 \%$, respectively). This study supported significant impact differences between victims of cyberbullying and control participants. Victims were elevated on psychological subscales of depression, anxiety, phobic anxiety, and paranoia, as well as the Global Severity Index (GSI) and Positive Symptom Total (PST) of the SCL-90-R when compared to control participants that had never experienced cyberbullying victimization. Victims were most frequently impacted by their victimization by feeling frustrated, stressed, sad or hurt, angry, and/or experienced difficulty concentrating.

Cyberbully victims endorsed significantly more suicidal behaviors than control participants. Exploratory analyses indicated victims of cyberbullying were significantly different from controls in their suicidal planning/attempts, frequency of suicidal ideations, and threats of suicide. This is consistent with and expands upon Hinduja and Patchin's (2010) study that found cyberbully victims (as well as perpetrators of cyberbullying and traditional bully perpetrators and victims) were more likely to experience suicidal thoughts and attempts.

Due to using a conservative significance criterion, there were no significant personality differences between victims and controls, but the personality characteristic of neuroticism was a strong trend. Although it has not been examined in previous research, there is a possible social desirability effect with the Five Factor Model Rating Form. Given the bipolar design and the adjective examples provided for each end point trait, there is an inherent desirable and less desirable answer choice. For example, the first question is about anxiousness and juxtaposes the adjectives fearful, apprehensive" with relaxed, unconcerned, cool." Regardless of the individual's actual characteristics, most people would prefer to be relaxed, unconcerned, and 
cool than fearful and apprehensive. As a result of this transparency, the potential of a social desirability effect is possible with this measure.

There were also no statistically significant differences in the impact based on the type of cyberbully victimization (e.g., Internet, picture/video messaging, masquerading) experienced. Qualitatively, of those four victims that endorsed previously attempting suicide, three had been victims of masquerading, among a constellation of other variations of victimization.

Coping strategies and behavioral responses to cyberbully victimization were mostly consistent between men and women. Both sexes told someone, avoided friends and/or peers, got revenge, or stopped attending events they once enjoyed in response to their victimization. The only difference was males chose to drink alcohol/use illegal drugs, whereas more females indicated they avoided the Internet or cell phones in response to cyberbully victimization. Additionally, when victims were given the opportunity to answer an open-ended question to freely express their coping strategies to being cyberbullied, the most common responses were: talking to someone, ignoring it, blocking it, and getting revenge.

The use of cyberbullying as a means to get revenge was systematically researched by Konig, Gollwitzer, and Steffgen (2010). Results of their study indicated that participants that were victims of traditional bullying chose to cyberbully those who perpetrated traditional bullying against them. This qualitatively coincides with the results of our study that victims of cyberbullying often perceived the motives of the perpetrators as revenge. Additionally, when victims were asked how they coped with being cyberbullied, got revenge" was a common response, perhaps perpetuating a cycle of bullying, both traditional and cyber.

Statistically there were no significant differences between male and female cyberbully victims (SCL-90-R, SBQ-R, FFMRF). However, qualitatively, there were minor variations in 
coping techniques, as well as differences in the type or topic of comments made about the victim (e.g., attacks on sexual orientation for males versus sexual activity for females).

\section{Limitations}

While this study yielded rich and interesting results, there were limitations that need to be addressed. This sample had many more female $(n=50)$ than male $(n=19)$ victims of cyberbullying. Obtaining a larger sample of cyberbully victims with more male representatives to better understand any potential sex differences in victimization is necessary.

The victim group was defined based solely on the dual-criteria of victimization. However, the Internet Experiences Questionnaire also contained questions about perpetrating cyberbullying. When examining these questions, $39.1 \%$ of victims $(n=27)$ were only victims and had not cyberbullied others, $33.3 \%$ of victims admitted to cyberbullying others two or three times $(n=23)$, and $27.5 \%$ of victims cyberbullied others four times or more $(n=19)$. Since this study was primarily concerned with victimization experiences, these groups were not specified. However, research on differences between victims-only, victims and bullies, bullies-only, and control participants is necessary for cyberbullying, as has been done with research on traditional bullying (Ragatz, Anderson, Fremouw, \& Schwartz, 2011).

Additionally, a dual-criterion was employed to define the group of cyberbully victims, which included behavioral criteria (endorsing experiencing cyberbullying acts four times or more) and identifying as a victim of cyberbullying. However, there were other participants that endorsed one component of this criterion, but not the other. For example, 69 participants identified as victims of cyberbullying, but did not endorse experiencing specific cyberbullying acts. Similarly, 58 participants endorsed experiencing four or more acts of cyberbullying victimization, but did not identify as victims. There were 594 -pure" control participants that 
denied being a victim of cyberbullying and did not endorse experiencing any acts of cyberbully victimization. This could not be determined for nine participants do to missing responses in their data. These differences were not teased out in this study and only pure" controls were compared to the 69 victims meeting dual criteria.

Although there were significant differences between psychological symptoms reported by cyberbully victims and controls in this study, it cannot be concluded that these reactions and responses directly resulted from their victimization. For example, victims were significantly different from controls in depression, anxiety, phobic anxiety, and paranoia. It is possible these psychological symptoms resulted from their cyberbully victimization. Alternatively, it is possible victims could have experienced more psychological distress in these areas and that contributed to others choosing them in particular to cyberbully. Also, it is possible that the differences in psychological symptoms are unrelated to cyberbully victimization status and may be related to other aspects of the individual's life and psychological functioning altogether. This same logic and possibility applies to the significant differences found between victims and controls regarding suicidal behaviors. A standardized clinical interview would help to better understand the onset or etiology of psychological distress and suicidal behaviors among cyberbully victim.

Additionally, another limitation of this study is that all data and results were based on self-report and none of the measures had built-in validity scales. Participants answered all questions about themselves anonymously and without any verification of their answers.

\section{Implications of Results}

The results of this study contribute empirical evidence to the effects cyberbullying can have on victims. Specifically, the differences in psychological symptomology and suicidal behaviors among victims are two primary areas that require additional research attention, as well 
as targeted intervention techniques. Similarly, the casual link between suicide attempts and victims of masquerading needs to be further explored. Logic serves there may be something inherently more impactful about masquerading that could have a greater effect on victims, even though this wasn't specifically found in our study.

School policies and state legislature are acting and evolving in response to cyberbullying. As a result, it is essential to recognize the serious impact cyberbullying is having on victims and intervene early and effectively. Most research and intervention programs have targeted elementary, middle, and high school students, as well as adults in the workforce. College students are a population that rely heavily on technologies, but have been overlooked in the cyberbullying research and literature. This study indicated that cyberbullying is still occurring in college and at a comparable rate to that found in another recent study (Kraft \& Wang, 2010). Intervention techniques and programs to prevent cyberbullying targeted at college students are necessary. Additionally, students that are victims of cyberbullying in college need to be aware and reminded of the resources and support available to them. Many of these students are separated from their family and close friends, often for the first time, and are unfamiliar with services available to help them cope with their victimization.

\section{Future Research Directions}

Cyberbullying is a growing phenomenon in our society and requires more research to understand the individuals choosing to cyberbully others, as well as the effects of cyberbullying on victims. Since this study revealed cyberbullying is occurring at a rate of $8.6 \%$ among a sample of college-students, research examining the characteristics of college-age perpetrators is now necessary, in order to get a complete picture of the cyberbullying phenomenon. Analyzing their motives, methods, and other variables, such as personality characteristics, will offer a better 
understanding of who is doing the victimization and ideally provide an intervention and prevention point.

Furthermore, studying the theory of what maintains cyberbullying is most appropriately done from the perspective of the perpetrator. While victims can offer perceived theories of what perpetuates the cyberbullying, there is a possibility their perceptions are not factual, or are misconstrued. As a result, this information is best directly obtained from the cyberbully him or herself.

Due to the difficulty in untangling the impact of cyberbullying from preexisting victim qualities that may have made them more vulnerable to victimization, longitudinal studies are needed. Longitudinal studies would allow researchers to examine the onset of these qualities in relation to cyberbullying victimization. Similarly, research focused on the victims who are repeatedly victimized across a variety of settings or situations would be beneficial to better understand repeated victimization and why it occurs. For example, why is someone who is bullied in middle school or high school bullied again in college when they are in a novel environment with new people? Having a better understanding of these particularly vulnerable individuals would allow for targeted intervention strategies for the victim and ideally prevent additional victimization from occurring.

Longitudinal studies would also help better understand the potential association between suicidal behaviors and cyberbully victimization. In a cross-sectional and longitudinal study conducted by Brunstein-Klomek and colleagues (2010), increased risk of suicidal ideation and suicide attempts were associated with bullying and cyberbullying above mere correlations. They found that the few longitudinal findings available indicate that bullying and peer victimization lead to suicidality but that this association varies by sex" (2010), but additional research is still 
needed to better understand this connection, the specific pathways and causal variables, as well as longitudinal studies focusing specifically on cyberbullying and its implications on suicidal behaviors.

Due to the novel nature of cyberbullying and research about it, future studies in almost all aspects of the phenomenon are necessary to better understand it and the characteristics of the individuals involved, both victims and perpetrators. There is a particular deficit of cyberbullying research at the college level. Given the increased dependence on technologies, both for academic purposes and personal communications, it is a gross oversight to not extend cyberbullying research to this population. More research is also necessary in order to develop effective intervention and prevention techniques among all populations of cyberbully victims. 


\section{References}

Beran, T. \& Li, Q. (2005). Cyber-harassment: A study of a new method for an old behavior. Journal of Educational Computing Research, 32, 265-277.

Bhat, C. S. (2008). Cyber bullying: Overview and strategies for school counsellors, guidance officers, and all school personnel. Australian Journal of Guidance and Counselling, 18, 53-66.

Brown, G. K. (2001). A review of suicide assessment measures for intervention research with adults and older adults. Retrieved from http://sbisrvntweb.uqac.ca/archivage /15290520.pdf. Accessed 15 February 2011.

Brunstein-Klomek, A., Sourander, A., \& Gould, M. (2010). The association of suicide and bullying in childhood to young adulthood: A review of cross-sectional and longitudinal research findings. Canadian Journal of Psychiatry, 55 (5), 282-288.

Campbell, M. A. (2005). Cyber bullying: An old problem in a new guise? Australian Journal of Guidance and Counselling, 15, 68-76.

Cole, D. A. (1988). Hopelessness, social desirability, depression, and parasuicide in two college student samples. Journal of Consulting and Clinical Psychology, 56 (1), 131-136.

Conners-Burrow, N. A., Johnson, D. L., Whiteside-Mansell, L., McKelvey, L., \& Gargus, R. A. (2009). Adult matter: Protecting children from the negative impacts of bullying. Psychology in the Schools, 46 (7), 593-604.

Dehue, F., Bolman, C., \& Völlink, T. (2008). Cyberbullying: Youngsters` experiences and parental perceptions. CyberPsychology \& Behavior, 11, 217-223. 
Dempsey, A. G., Sulkowski, M. L., Nichols, R., \& Storch, E. A. (2009). Differences between peer victimization in cyber and physical settings and associated psychosocial adjustment in early adolescence. Psychology in the Schools, 46 (10), 962-972.

Derogatis, L. R. (1994). Symptom Checklist-90-R: Administration, scoring, and procedures manual ( $3^{\text {rd }}$ ed.). Minneapolis, MN: National Computer Systems.

Due, P., Merlo, J., Harel-Fisch, Y., Damsgaard, M. T., Holstein, B. E., Hetland, J., Currie, C., Gabhainn, S. N., Gaspar de Matos, M., \& Lynch, J. (2009). Socioeconomic inequality in exposure to bullying during adolescence: A comparative, cross-sectional, multilevel study in 35 countries. American Journal of Public Health, 99 (5), 907-914.

Fauman, M. A. (2008). Review of Cyber bullying: Bullying in the digital age“. The American Journal of Psychiatry, 165, 780-781.

Finkelhor, D., Mitchell, K. J., \& Wolak, J. (2000). Online victimization: A report on the nation's youth. Alexandria, VA: National Center for Missing and Exploited Children.

Friedman, E. (2010., September 29). Victim of secret dorm sex tape posts Facebook goodbye, jumps to his death. ABC News. Retrieved from http://abcnews.go.com/US/victim-secretdorm-sex-tape-commits-suicide/story? $\mathrm{id}=11758716$.

Hinduja, S. \& Patchin, J. W. (2010). Bullying, cyberbullying, and suicide. Archives of Suicide Research, 14, 206-221.

Hinduja, S. \& Patchin, J. W. (2009). Cyberbullying fact sheet: A brief review of relevant legal and policy issues. Retrieved from www.cyberbullying.us

Hinduja, S. \& Patchin, J. W. (2008). Cyberbullying: An exploratory analysis of factors related to offending and victimization. Deviant Behavior, 29, 129-156. 
Hinduja, S. \& Patchin, J.W. (2007). Offline consequences of online victimization: School violence and delinquency. Journal of School Violence, 6, 89-112.

Internet users as percentage of population. (2009, November 20). Retrieved from World Bank, World development Indicators from http://www.google.com/publicdata?ds=wbwdi\&met=it_net_user_p2\&idim=country:USA\&q=Internet + usage + statistics

Johnson, O. (2010, January 23). Bullying eyed in girl's death. Boston Herald. Retrieved from http://news.bostonherald.com/news/regional/view/20100123bullying_eyed_in_girls_deat $\mathrm{h} / \mathrm{srvc}=$ home $\&$ position $=$ also

Kraft, E. \& Wang, J. (2010). An exploratory study of the cyberbullying and cyberstalking experiences and factors related to victimization of students at a public liberal arts college. International Journal of Technologies, 1 (4), 74-91.

Konig, A., Gollwitzer, M., \& Steffgen, G. (2010). Cyberbullying as an act of revenge? Australian Journal of Guidance and Counselling, 20 (2), 210-224.

Li, Q. (2007a). Bullying in the new playground: Research into cyberbullying and cyber victimization. Australian Journal of Educational Technology, 23, 435-454.

Li, Q. (2007b). New bottle but old wine: A research of cyberbullying in schools. Computers in Human Behavior, 23, 1777-1791.

Linehan, M. M., \& Nielsen, S. L. (1981). Assessment of suicide ideation and parasuicide: Hopelessness and social desirability. Journal of Consulting and Clinical Psychology, 49 (5), 773-775.

Mason, K. L. (2008). Cyberbullying: A preliminary assessment for school personnel. Psychology in the Schools, 45, 323-348. 
Maxwell, A. (2001, June). Cyberstalking. (Master's thesis, Auckland University). Retrieved from http://www.netsafe.org.nz/Doc_Library/cyberstalking.pdf

McCrae, R. R. \& Costa, P. T. (1987). Validation of the five-factor model of personality across instruments and observers. Journal of Personality and Social Psychology, 52, 81-90.

Olweus, D. (1993). Bullying at school: What we know and what we can do. Oxford, UK: Blackwell Publishing.

Parents: Cyber bullying led to teen's suicide. (2007, November 19). Retrieved from the Good Morning America Official Site website: http://abcnews.go.com/GMA/story?id $=3882520$ \&page $=1$

Patchin, J. W. \& Hinduja, 2. (2010). Cyberbullying and self-esteem. Journal of School Health, $80(12), 614-621$.

Patchin, J. W. \& Hinduja, S. (2006). Bullies move beyond the schoolyard: A preliminary look at cyberbullying. Youth Violence and Juvenile Justice, 4, 148-169.

Privitera, C. \& Campbell, M. (2009). Cyberbullying: The new face of workplace bullying? CyberPsychology \& Behavior, 12, 395-400.

Ragatz, L.L., Anderson, R.J., Fremouw, W., \& Schwartz, R. (2011). Criminal thinking patterns, aggression styles, and the psychopathic traits of late high school bullies and bullyvictims. Aggressive Behavior, 37 (2), 145-160.

Raskauskas, J. \& Stoltz, A. D. (2007). Involvement in traditional and electronic bullying among adolescents. Developmental Psychology, 43, 564-575.

Rigby, K. (June 2003). Addressing bullying in schools: Theory and practice. Australian Institute of Criminology. Retrieved from http://aic.gov.au/documents/D/A/2 /\%7BDA2B9086-7A46-4CBB-B065-86B05BD2EA6C\%7Dtandi259.pdf. 
Slonje, R. \& Smith, P. K. (2008). Cyberbullying: Another main type of bullying? Scandinavian Journal of Psychology, 49, 147-154.

Smith, P. K., Mahdavi, J., Carvalho, M., Fisher, S., Russell, S., \& Tippett, N. (2008). Cyberbullying: Its nature and impact in secondary school pupils. Journal of child Psychology and Psychiatry, 49, 376-385.

Smith, P. K., Shu, S., \& Madsen, K. (2001). Characteristics of victims of school bullying: Developmental changes in coping strategies and skills. In J. Juvonen \& S. Graham (Eds.), Peer harassment in school: Plight of the vulnerable and victimized (pp. 332-352).

Sourander, A., Brunstein-Klomek, A., Ikonen, M., Lindroos, J., Luntamo, T., Koskelainen, M., Ristkari, T., \& Helenius, H. (2010). Psychological risk factors associated with cyberbullying among adolescents: A population-based study. Archieve of General Psychiatry, 67 (7), 720-728.

Sutton, J., Smith, P. K., \& Swettenham, J. (1999). Bullying and theory of mind': A critique of the social skills deficit‘ view of anti-social behavior. Social Development, 8, 117-127.

Thomas, S. P. (2006). From the editor: The phenomenon of cyberbullying. Issues in Mental Health Nursing, 27, 1015-1016.

Todd, D. M., Deane, F. P., \& McKenna, P. A. (1997). Appropriateness of SCL-90-R adolescent and adult norms for outpatient and nonpatient college students. Journal of Counseling Psychology, 44, 294-301.

Vandebosch, H. \& Van Cleemput, K. (2008). Defining cyberbullying: A qualitative research into the perceptions of youngsters. CyberPsychology \& Behavior, 11, 499-503.

Westrup, D. \& Fremouw, W. J. (1998). Stalking behavior: A literature review and suggested functional analytic assessment technology. Aggression and Violent Behavior, 3, 255-274. 
Widiger, T. (2003). Personality disorder and Axis I psychopathology: The problematic boundary of Axis I and Axis II. Journal of Personality Disorders, 17(2), 90-108.

Widiger, T. A. \& Lowe, J. R. (2007). Five-factor model assessment of personality disorder. Journal of Personality Assessment, 89, 16-29.

Willard, N. E. (2007). Cyberbullying and cyberthreats: Responding to the challenge of online social aggression, threats, and distress. United States of America: Malloy, Inc.

Ybarra, M. L., Mitchell, K. J., Wolak, J., \& Finkelhor, D. (2006). Examining characteristics and associated distress related to internet harassment: Findings from the second youth internet safety survey. Pediatrics, 118, 1169-1177.

Ybarra, M. L. \& Mitchell, K. J. (2004). Youth engaging in online harassment: Associations with caregiver-child relationships, internet use, and personal characteristics. Journal of Adolescence, 27, 319-336.

Ybarra, M. L. (2004). Linkages between depressive symptomatology and internet harassment among young regular internet users. CyberPsychology \& Behavior, 7, 247-257.

Zuckerman, M. (2002). Zuckerman-Kuhlman personality questionnaire (ZKPQ): An alternative five-factorial model. In B. de Raad, \& M. Perugini (Eds.), Big Five Assessment. Ashland, OH: Hogrefe \& Huber Publishers (pp. 376-392). 
Figure 1. The relationship between traditional bullying, cyberbullying, and stalking behaviors.

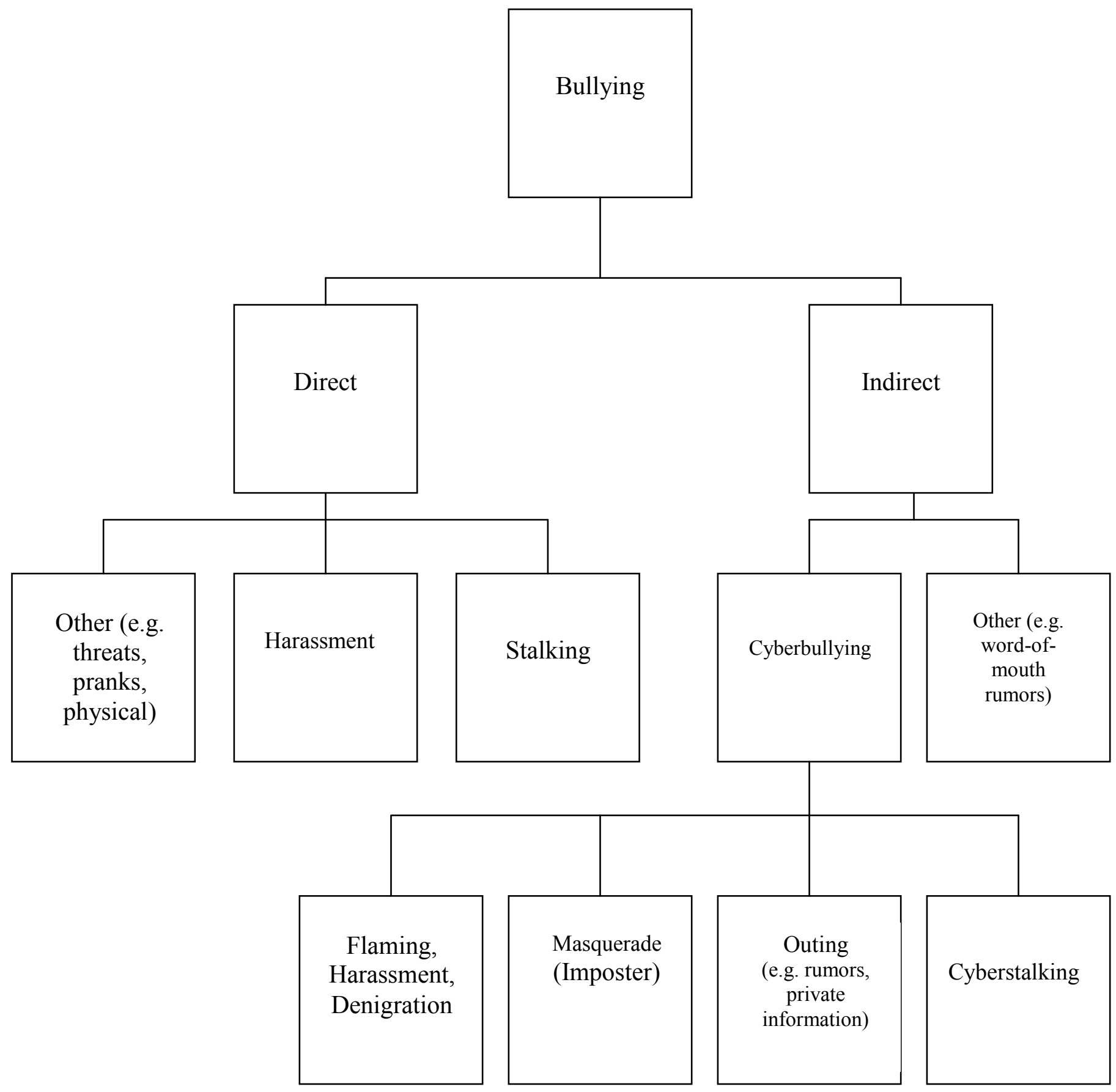


Table 1

Descriptive data for cyberbully victims and the control group

\begin{tabular}{|c|c|c|c|c|}
\hline & \multicolumn{2}{|c|}{ Cyberbully Victims } & \multicolumn{2}{|c|}{ Control } \\
\hline & $M$ & $S D$ & $M$ & $S D$ \\
\hline Age in years & 19.93 & 1.44 & 19.93 & 1.44 \\
\hline GPA & 3.07 & 0.57 & 3.10 & 0.59 \\
\hline Average hours online/day & 3.99 & 2.35 & 3.57 & 1.70 \\
\hline \multirow[t]{2}{*}{ Dollars spent on technology/month } & 59.64 & 56.28 & 53.83 & 55.02 \\
\hline & $n$ & $\%$ & $n$ & $\%$ \\
\hline \multicolumn{5}{|l|}{ Participant gender } \\
\hline Female & 50 & 72.5 & 50 & 72.5 \\
\hline Male & 19 & 27.5 & 19 & 27.5 \\
\hline \multicolumn{5}{|l|}{ Class rank } \\
\hline Freshman & 13 & 18.8 & 16 & 23.2 \\
\hline Sophomore & 27 & 39.1 & 29 & 42.0 \\
\hline Junior & 14 & 20.3 & 12 & 17.4 \\
\hline Senior & 15 & 21.7 & 12 & 17.4 \\
\hline \multicolumn{5}{|l|}{ Marital Status } \\
\hline Married & 1 & 1.4 & 0 & 0 \\
\hline Single & 67 & 97.1 & 69 & 100.0 \\
\hline Divorced & 0 & 0 & 0 & 0 \\
\hline Widowed & 0 & 0 & 0 & 0 \\
\hline \multicolumn{5}{|l|}{ Ethnicity } \\
\hline White & 61 & 88.4 & 63 & 91.3 \\
\hline Other & 8 & 11.6 & 6 & 8.7 \\
\hline \multicolumn{5}{|l|}{ Utilized mental health services } \\
\hline Yes & 18 & 26.1 & 16 & 23.2 \\
\hline No & 51 & 73.9 & 52 & 75.4 \\
\hline
\end{tabular}


Table 2

Means for the Symptom Checklist-90-Revised (SCL-90-R) subscales and Additional Scales for cyberbully victims and control group

\begin{tabular}{|c|c|c|c|c|c|c|c|}
\hline & \multicolumn{2}{|c|}{$\begin{array}{c}\text { Cyberbully Victim } \\
\qquad N=69\end{array}$} & \multicolumn{2}{|c|}{$\begin{array}{l}\text { Control } \\
N=69\end{array}$} & \multirow[b]{2}{*}{$F$} & \multirow[b]{2}{*}{$p$} & \multirow[b]{2}{*}{$\begin{array}{c}\text { Partial } \\
\eta^{2}\end{array}$} \\
\hline & $M$ & $S D$ & $M$ & $S D$ & & & \\
\hline \multicolumn{8}{|l|}{ SCL-90-R } \\
\hline Somatic & 58.81 & 12.29 & 53.28 & 11.39 & 6.85 & .010 & .049 \\
\hline OCD & 59.42 & 12.18 & 57.38 & 10.41 & .915 & .340 & .007 \\
\hline Interpersonal & 58.17 & 13.16 & 52.94 & 12.23 & 6.62 & .011 & .047 \\
\hline \multicolumn{8}{|l|}{ Sensitivity } \\
\hline Depression & 61.13 & 10.91 & 56.45 & 10.34 & 9.90 & $.002 *$ & .069 \\
\hline Anxiety & 57.20 & 13.34 & 52.54 & 10.75 & 9.11 & $.003 *$ & .064 \\
\hline Hostility & 57.23 & 10.70 & 52.42 & 9.55 & 6.65 & .011 & .047 \\
\hline Phobic Anxiety & 56.29 & 11.92 & 51.23 & 9.24 & 8.66 & $.004 *$ & .061 \\
\hline Paranoid & 56.77 & 12.54 & 49.99 & 10.53 & 12.20 & $.001 *$ & .083 \\
\hline Psychotic & 58.41 & 14.30 & 52.99 & 12.11 & 6.54 & .012 & .047 \\
\hline \multicolumn{8}{|c|}{ Additional Scales (SCL-90-R) } \\
\hline GSI & 60.01 & 12.95 & 54.83 & 10.91 & 8.01 & $.005^{*}$ & .056 \\
\hline PST & 59.59 & 13.47 & 53.84 & 11.21 & 9.51 & $.002 *$ & .066 \\
\hline PSDI & 57.12 & 9.29 & 55.33 & 9.13 & .293 & .589 & .002 \\
\hline
\end{tabular}

Note. Wilks' lambda $=.807, p=.001$. A significant value of $p<.0055$ used with Bonferroni corrections for SCL-90-R scales. A significance value of $p<.0167$ was used with Bonferroni corrections for the Additional Scales (SCL-90-R). GSI = Global Severity Index, PST = Positive Symptom Total, PSDI = Positive Symptom Distress Index. 
Table 3

Impacts of cyberbully victimization as derived from the Internet Experiences Questionnaire

\begin{tabular}{|c|c|c|c|}
\hline & $\begin{array}{l}\text { Never } \\
n(\%)\end{array}$ & $\begin{array}{l}\text { Sometimes } \\
n(\%)\end{array}$ & $\begin{array}{l}\text { Frequent } \\
n(\%)\end{array}$ \\
\hline Frustrated & $1(1.5)$ & $34(52.3)$ & $30(46.2)$ \\
\hline Stressed & $17(25.8)$ & $22(33.3)$ & $27(40.9)$ \\
\hline Sad or hurt & $14(21.2)$ & $27(40.9)$ & $25(37.9)$ \\
\hline Angry & $8(12.3)$ & $35(53.8)$ & $22(33.8)$ \\
\hline Difficulty concentrating & $25(39.1)$ & $24(37.5)$ & $15(23.4)$ \\
\hline Cried & $26(40.0)$ & $25(38.5)$ & $14(21.5)$ \\
\hline Anxious & $27(41.5)$ & $24(36.9)$ & $14(21.5)$ \\
\hline Embarrassed & $22(33.3)$ & $32(48.5)$ & $12(18.8)$ \\
\hline Thought about it constantly & $25(38.5)$ & $28(43.1)$ & $12(18.5)$ \\
\hline Helpless/hopeless & $39(59.1)$ & $15(22.7)$ & $12(18.2)$ \\
\hline Jumpy/irritable & $32(48.5)$ & $23(34.8)$ & $11(16.7)$ \\
\hline Grades dropped & $48(72.7)$ & $10(15.2)$ & $8(12.1)$ \\
\hline Acted out & $40(60.6)$ & $18(27.3)$ & $8(12.1)$ \\
\hline Blamed myself & $38(57.6)$ & $21(31.8)$ & $7(10.6)$ \\
\hline Missed school & $45(68.2)$ & $15(22.7)$ & $6(9.1)$ \\
\hline Afraid & $36(54.5)$ & $24(36.4)$ & $6(9.1)$ \\
\hline
\end{tabular}

Note. Percentages were based off of cyberbully victims that answered the question. It does not include those who did not answer by selecting Đecline to answer." 
Table 4

Frequencies of suicidal planning and attempts

\begin{tabular}{lcccc}
\hline & $\begin{array}{c}\text { Never } \\
n(\%)\end{array}$ & $\begin{array}{c}\text { Ideation } \\
n(\%)\end{array}$ & $\begin{array}{c}\text { Plan } \\
n(\%)\end{array}$ & $\begin{array}{c}\text { Attempt } \\
n(\%)\end{array}$ \\
\hline Cyberbully Victims & $34(49.3)$ & $20(29.0)$ & $11(15.9)$ & $4(5.7)$ \\
Control Participants & $48(69.6)$ & $13(18.8)$ & $7(10.1)$ & $0(0.0)$ \\
\hline
\end{tabular}

Note. $X^{2}(3, N=138)=9.09, p=.028$. 
Table 5

Frequency of Suicidal Ideations

\begin{tabular}{lccc}
\hline & $\begin{array}{c}\text { Never } \\
n(\%)\end{array}$ & $\begin{array}{c}\text { Rarely/Sometimes } \\
n(\%)\end{array}$ & $\begin{array}{c}\text { Often/Very Often } \\
n(\%)\end{array}$ \\
\hline Cyberbully Victims & $49(71.0)$ & $13(18.8)$ & $7(10.1)$ \\
Control Participants & $54(78.3)$ & $14(20.3)$ & $0(0.0)$ \\
\hline
\end{tabular}

Note. $X^{2}(3, N=138)=9.09, p=.028$. 
Table 6

Frequency of Suicidal Threats

\begin{tabular}{lccc}
\hline & $\begin{array}{c}\text { Never } \\
n(\%)\end{array}$ & $\begin{array}{c}\text { One short period of time } \\
n(\%)\end{array}$ & $\begin{array}{c}\text { More than one period of time } \\
n(\%)\end{array}$ \\
\hline Cyberbully Victims & $55(79.7)$ & $10(14.5)$ & $4(5.8)$ \\
Control Participants & $63(91.3)$ & $4(5.8)$ & $1(1.4)$
\end{tabular}

Note. Chi-square test of goodness-of-fit was not significant. 
Table 7

Means for the Five Factor Model Rating Form (FFMRF)

\begin{tabular}{lccccccc}
\hline & \multicolumn{2}{c}{$\begin{array}{c}\text { Cyberbully Victim } \\
\text { Control }\end{array}$} & & & \\
& \multicolumn{2}{c}{$(n=69)$} & $(n=69)$ & & & \\
\cline { 2 - 7 } & $M$ & $S D$ & $M$ & $S D$ & $F$ & $p$ & $\begin{array}{c}\text { Partial } \\
\eta^{2}\end{array}$ \\
\hline Neuroticism & 16.57 & 4.56 & 14.70 & 4.32 & 6.52 & .012 & .046 \\
Extraversion & 22.16 & 4.11 & 21.12 & 3.29 & .852 & .358 & .006 \\
Openness & 20.67 & 2.82 & 20.29 & 3.02 & 1.58 & .210 & .012 \\
Agreeableness & 21.09 & 3.44 & 21.80 & 2.86 & 1.30 & .257 & .010 \\
Conscientiousness & 21.38 & 4.17 & 21.61 & 3.36 & .039 & .844 & .000 \\
\hline
\end{tabular}

Note. A significant value $p<.01$ with Bonferroni correction was utilized. 
Table 8

Cyberbullying and subtype prevalence rates

\begin{tabular}{lccc}
\hline & $\begin{array}{c}\text { Females } \\
n(\%)\end{array}$ & $\begin{array}{c}\text { Males } \\
n(\%)\end{array}$ & $\begin{array}{c}\text { Total } \\
n(\%)\end{array}$ \\
\hline Overall Cyberbullying & $50(100.0)$ & $19(100.0)$ & $69(100)$ \\
Text Messaging & $45(90.0)$ & $17(89.5)$ & $61(89.9)$ \\
Internet & $17(34.0)$ & $4(21.1)$ & $21(30.4)$ \\
Picture Video & $10(20.0)$ & $5(26.3)$ & $15(21.7)$ \\
Phone Calls & $35(70.0)$ & $14(73.7)$ & $49(71.0)$ \\
Masquerading & $14(28.0)$ & $5(26.3)$ & $19(27.5)$ \\
\hline
\end{tabular}

Note. These categories are subset forms of cyberbullying are not mutually exclusive and participants were allowed to endorse all variations that applied. The total percentages for the types of cyberbullying represent the percentage of victims experiencing that form of victimization. The percentages for females and males are sex-specific for the various forms of victimization. 
Table 9

Most frequent behavioral responses to cyberbully victimization by gender

$\begin{array}{lc}\text { Female } & \text { Male } \\ (n=50) & (n=19)\end{array}$

1. Told Someone (40)

2. Avoided friends or peers (19)

3. Avoided the Internet/cell phones

4. Got revenge (13)

5. Stopped going to events (10)
1. Told someone (10)

2. Avoided friends or peers (6)

2. Got revenge (6)

3. Drank alcohol/use illegal drugs (4)

3. Stopped going to events (4)

Note. Participants were allowed to select as many options as applicable to adequately describe their behavioral reactions to their experiences. 
Table 10

Topics of attacks made to or about cyberbully victims

\begin{tabular}{lcc}
\hline \multicolumn{1}{c}{ Topic } & Female, $n=50$ & Male, $n=19$ \\
& $n(\%)$ & $n(\%)$ \\
\hline Self-Worth & $34(68.0)$ & $6(47.4)$ \\
Sexual Activity & $22(44.0)$ & $7(36.8)$ \\
Appearance & $19(38.0)$ & $4(21.1)$ \\
Intelligence & $16(32.0)$ & $1(5.3)$ \\
Social Status (e.g., popularity, loser) & $14(28.0)$ & $8(42.1)$ \\
Sexual Orientation & $2(4.0)$ & $0(0.0)$ \\
Religion & $2(4.0)$ & $1(5.3)$ \\
Race & $1(2.0)$ & \\
\hline
\end{tabular}

Note. These categories were not mutually exclusive and participants were allowed to select all that applied to their experiences. 


\section{APPENDIX A - Internet Experiences Questionnaire (IEQ)}

Tell us about yourself:

The following questions address information regarding your personal characteristics and experiences. Please answer the following questions as honestly as possible. If you feel uncomfortable answering any questions you may decline to answer it.

1. What is your age?

2. What is your gender? (check one):

Female Male

3. With what ethnic group do you most closely identify? (check one)

White/Caucasian Native American
Black/African American Asian American
Latino/Hispanic Other

4. Marital Status: (check one):

Married

Widowed

Single

Divorced

Separated

5. What is your current class status? (check one):

Freshman Sophomore Junior Senior

Graduate Student

Other

6. What is your current GPA?

7. Have you ever sought mental health counseling?

Yes No

8. Approximately how many hours are you online on a typical day?

9. On average, how much money do you spend each month on Internet and cell phone bills?

\section{YOUR EXPERIENCES (PERPETRATOR SECTION)}

10. Since you've been at WVU, how many times have you:

a. Sent mean, nasty, or harassing messages to someone via the Internet or cellular phone?

$$
\begin{array}{llllll}
0 & 1 & 2-3 & 4-7 & 8-14 & 15 \text { or more }
\end{array}
$$

b. Put down someone else online by sending or posting cruel gossip, rumors, or other harmful material?

$$
\begin{array}{llllll}
0 & 1 & 2-3 & 4-7 & 8-14 & 15 \text { or more }
\end{array}
$$

c. Pretended to be someone else online to send or post material to damage that person's reputation or friendships?

$$
\begin{array}{llllll}
0 & 1 & 2-3 & 4-7 & 8-14 & 15 \text { or more }
\end{array}
$$

d. Shared someone's personal secrets or images online without that person's permission?

$$
\begin{array}{llllll}
0 & 1 & 2-3 & 4-7 & 8-14 & 15 \text { or more }
\end{array}
$$


11. How many different people did you do these things to using the Internet or cell phones?

$\begin{array}{lllll}0 & 1 & 2-3 & 4-6 & 7 \text { or more }\end{array}$

12. What methods of technology did you use to send harassing or mean messages to others and/or to post material to damage the reputation/relationships of others? (Please select all that apply):

Email

Instant messaging

Social networking sites

Blogs/website creation

Text messaging

Picture messaging

Video messaging

Repeated phone calls (prank calling)

I have never sent harassing or mean messages or posted material to damage

relationships/reputations of others.

13. If you have pretended to be someone else online to send or post material to damage that person's reputation or friendships, who did you pretend to be?

I've never pretended to be someone else online

I pretended to be the person I was posting information about

I pretended to be a member of the opposite sex seeking a relationship

I pretended to be one of their friends

Other: Please describe:

Not applicable

14. What were your reasons for doing these behaviors via the Internet/Cellular phones? (please select all that apply):

Anger

Jealousy

Revenge

Hatred

Dislike for the other person

Sadness

Attention

Boredom

To try to make up with an ex-boyfriend/girlfriend

To try to disrupt/ruin a friendship

To try to disrupt/ruin a romantic relationship

Revenge for being bullied by others

Other: Please describe

Not applicable 
15. How do you think this impacted the other person? (If this question is not applicable to you, please select_decline to answer'):

16. What were your reasons for choosing who to send mean/harassing messages to, posting material to damage the reputation/relationships of others, etc. (please select all that apply):

You disliked them

You were mad at them

To get revenge

To hurt the person

They are a weak/less powerful individual

They physically bullied you

They were annoying

Other: Please describe:

Not applicable

17. If you stopped, why did you stop? (If this question is not applicable to you, please select _decline to answer') :

18. Did you stop for any of the following reasons? (Please select all that apply) No longer $\mathrm{mad} / \mathrm{upset}$

Got bored with it Could no longer contact the person Didn't want to hurt the persons feelings

Got caught by parents or other adults

Got caught by the police

Other: Please describe:

Not applicable

\section{Your Experiences}

For this section, bullying is when someone repeatedly says mean or hurtful things to another individual. This includes teasing, hitting or fighting, threats, leaving you out on purpose, or telling lies or starting rumors about you.

19. Since you've been at WVU, have you ever been bullied? Yes No

20. Have you ever been bullied in middle school and/or high school?

$$
\text { Yes No }
$$

Cyberbullying is defined as repeatedly harassing someone using technology such as email, instant messaging, social networking sites, blogs, other websites, cell phones, text messaging, picture messaging, video messaging, etc. with the intent of harming, embarrassing, or damaging 
the other individual. Cyberbullying also includes a person pretending to be someone they are not to embarrass, harass, or harm others.

TEXT MESSAGING

21. During your time at WVU, have you received harassing, mean, or nasty text-messages? Yes No

22. How many times did this occur?

$$
\begin{array}{llllll}
0 & 1 & 2-3 & 4-7 & 8-14 & 15 \text { or more }
\end{array}
$$

23. If yes to Question _, who sent the harassing, mean, or nasty text messages to you? (Please check all that apply)

Ex-Boyfriend/Girlfriend

Neighbor

Not applicable
Friend/former friend Uncertain
Classmate

Other (please describe):

\section{INTERNET}

24. During your time at WVU, have you ever been had someone create a website about you, use your pictures on-line without your permission, post damaging or embarrassing information about you, create forums about you, repeatedly send you harassing emails or instant messages, receive abusive chat room messages, etc?

Yes No

25. How many times did this occur?

$\begin{array}{llllll}0 & 1 & 2-3 & 4-7 & 8-14 & 15 \text { or more }\end{array}$

26. If yes to Question __, who was doing it? (Please check all that apply) Ex-Boyfriend/Girlfriend Neighbor Friend/former friend Classmate Uncertain Other (please describe): Not applicable

\section{PICTURE/VIDEO PHONES}

27. During your time at WVU, have you ever had someone take embarrassing or degrading pictures or videos of you with picture/video phones without your permission and show the pictures/videos to others to embarrass you? Yes No

28. How many times did this occur?

$$
\begin{array}{llllll}
0 & 1 & 2-3 & 4-7 & 8-14 & 15 \text { or more }
\end{array}
$$

29. If yes to Question ___, who was doing it? (Please check all that apply) Ex-Boyfriend/Girlfriend Neighbor Friend/former friend Uncertain Classmate Not applicable Other (please describe): 


\section{PHONE CALLS}

30. During your time at WVU, have you ever been repeatedly called on your mobile phone by a person/people not saying anything or leaving nasty/upsetting messages? Yes No

31. How many times did this occur?

$$
\begin{array}{llllll}
0 & 1 & 2-3 & 4-7 & 8-14 & 15 \text { or more }
\end{array}
$$

32. If yes to Question __, who was doing it? (Please check all that apply) Ex-Boyfriend/Girlfriend Neighbor Friend/former friend Uncertain Classmate Not applicable

Other (please describe):

\section{MASQUERADING}

33. During your time at WVU, have you ever had someone pretend to be someone they were not and post or send material to damage your friendships or reputation, and/or hurt or embarrass you? Yes No

34. How many times did this occur?

$$
\begin{array}{llllll}
0 & 1 & 2-3 & 4-7 & 8-14 & 15 \text { or more }
\end{array}
$$

35. If yes to Question __ , who was doing it? (Please check all that apply) Ex-Boyfriend/Girlfriend Neighbor Friend/former friend Uncertain Classmate Not applicable

36. If you have encountered someone using the Internet or cellular phones pretending to be someone they were not, did they pretend to be you or someone else?
$\mathrm{Me}$
Someone else
Both

GENERAL CYBERBULLYING

37. Since you've been at WVU, have you been a victim of cyberbullying?
Yes
No

38. Since middle school and/or high school, have you ever experienced cyberbullying?

\section{Yes No}

39. If you have been cyberbullied in any way (texts, pictures or video-clips, email, website, chat-rooms, mobile phone calls, or other), what sorts of comments/remarks were made? (Please check all that apply)

Appearance

Race

Sexual Orientation

Sexual Activity

Intelligence

Self-worth 
Religion

Social status

Other: Please describe.

I have never been cyberbullied

40. If you have been the victim of cyberbullying, what was the reason someone did this to you? (If you have never been a victim of cyberbullying, please select decline to answer)

41. What do you think the motive was for someone to cyberbully you? (Please check all that apply):

Jealousy

Anger

Revenge

Just to be mean/hurtful

To embarrass you

Other: Please describe:

I have never been cyberbullied.

\section{IMPACT/COPING}

42. If you were the victim of cyberbullying, how did it impact you? (If you have never been a victim of cyberbullying, please select decline to answer)

43. If you were a victim of cyberbullying, did you do any of the following things as a result of being cyberbullied? (Please select all that apply)

Avoid friends/peers

Tell someone what was happening (friends, family, trusted adult, etc.)

Miss class

Stop going to activities you once attended

Lose interest in things

Grades dropped in school

Acted out behaviors (e.g. stealing, truancy, substance use, etc.)

Drop-out of school

Drink alcohol/use illegal drugs

Get revenge

Consciously avoid the Internet/cell phones

Carry a weapon or something to defend yourself

Other: Please describe:

I have never been cyberbullied.

44. If you were a victim of cyberbullying, how did you cope with the experience? (If you have never been a victim of cyberbullying, please select decline to answer) 
45. If you were a victim of cyberbullying, did you do any of the following things to cope? (Please select all that apply):

Talk about the experience with a friend

Talk about the experience with a parent or trusted adult

Ignore it

Stay off the Internet and/or your cell phone

Remove personal information from certain websites (particularly social networking sites)

Blocked certain people from contacting you on the Internet and/or your cell phone

Confront the person doing it

Ask the person doing it to stop

Sent mean, harassing, or embarrassing information back

Use physical force to convince the person to stop (beat them up)

Contact the police

Contact your service provider

Change your phone number, email address, or other identifying information

Other: Please describe:

I have never been cyberbullied.

46. If you were a victim of cyberbullying, how did you get the harassment to stop? Please describe: (If you have never been a victim of cyberbullying, please select decline to answer.)

47. If you were a victim of cyberbullying, how have you been impacted? (If you have never been a victim of cyberbullying, please select decline to answer.)

a. I felt sad or hurt

1-Never 2-Once/twice 3-A few times 4-Many times 5-Almost every day

b. I felt angry

1-Never 2-Once/twice 3-A few times 4-Many times 5-Almost every day

c. I felt embarrassed

1-Never 2-Once/twice 3-A few times 4-Many times 5-Almost every day

d. I felt afraid

1-Never 2-Once/twice 3-A few times 4-Many times 5-Almost every day

e. I felt anxious

1-Never 2-Once/twice 3-A few times 4-Many times 5-Almost every day

f. I felt helpless and/or hopeless

1-Never 2-Once/twice 3-A few times 4-Many times 5-Almost every day

g. I felt frustrated

1-Never 2-Once/twice 3-A few times 4-Many times 5-Almost every day

h. I was stressed 
1-Never 2-Once/twice 3-A few times 4-Many times 5-Almost every day

f. I missed school because of it

1-Never 2-Once/twice 3-A few times 4-Many times 5-Almost every day

g. I cried

1-Never 2-Once/twice 3-A few times 4-Many times 5-Almost every day

h. I had difficulty concentrating

1-Never 2-Once/twice 3-A few times 4-Many times 5-Almost every day

i. My grades have dropped because of it

1-Never 2-Once/twice 3-A few times 4-Many times 5-Almost every day

j. I became jumpy or irritable

1-Never 2-Once/twice 3-A few times 4-Many times 5-Almost every day

$\mathrm{k}$. I thought about the online harassment almost constantly

1-Never 2-Once/twice 3-A few times 4-Many times 5-Almost every day

i. I acted out

1-Never 2-Once/twice 3-A few times 4-Many times 5-Almost every day

j. I blamed myself

1-Never 2-Once/twice 3-A few times 4-Many times 5-Almost every day

$\mathrm{k}$. I had thoughts of suicide

1-No 2-Yes, without a plan 3-Yes, with a plan 4-Yes, with an attempt 


\section{APPENDIX B - Symptom Checklist-90-R}

Instructions: Below is a list of problems people sometimes have. Please read each on carefully, and select the option that best describes HOW MUCH THAT PROBLEM HAS DISTRESSED OR BOTHERED YOU DURING THE PAST 7 DAYS INCLUDING TODAY. Choose only one option for each question and do not skip any items. If you change your mind, you may choose another answer before moving on to the next section of this study.

$0=$ Not at all $1=$ A little bit $\quad 2=$ Moderately $\quad 3=$ Quite a bit $\quad 4=$ Extremely

How much were you distressed by:

1. Headaches

$\begin{array}{lllll}0 & 1 & 2 & 3 & 4\end{array}$

2. Nervousness or shakiness inside

$\begin{array}{lllll}0 & 1 & 2 & 3 & 4\end{array}$

3. Repeated unpleasant thoughts that won't leave your mind

$\begin{array}{lllll}0 & 1 & 2 & 3 & 4\end{array}$

4. Faintness or dizziness

$\begin{array}{lllll}0 & 1 & 2 & 3 & 4\end{array}$

5. Loss of sexual interest or pleasure

$\begin{array}{lllll}0 & 1 & 2 & 3 & 4\end{array}$

6. Feeling critical of others

$\begin{array}{lllll}0 & 1 & 2 & 3 & 4\end{array}$

7. The idea that someone else can control your thoughts

$\begin{array}{lllll}0 & 1 & 2 & 3 & 4\end{array}$

8. Feeling others are to blame for most of your troubles

$\begin{array}{lllll}0 & 1 & 2 & 3 & 4\end{array}$


9. Trouble remembering things

$\begin{array}{lllll}0 & 1 & 2 & 3 & 4\end{array}$

10. Worried about sloppiness or carelessness

$\begin{array}{lllll}0 & 1 & 2 & 3 & 4\end{array}$

11. Feeling easily annoyed or irritated

$\begin{array}{lllll}0 & 1 & 2 & 3 & 4\end{array}$

12. Pains in heart or chest

$\begin{array}{lllll}0 & 1 & 2 & 3 & 4\end{array}$

13. Feeling afraid in open spaces or on the streets

$\begin{array}{lllll}0 & 1 & 2 & 3 & 4\end{array}$

14. Feeling low in energy or slowed down

$\begin{array}{lllll}0 & 1 & 2 & 3 & 4\end{array}$

15. Thoughts of ending your life

$\begin{array}{lllll}0 & 1 & 2 & 3 & 4\end{array}$

16. Hearing voices that other people do not hear

$\begin{array}{lllll}0 & 1 & 2 & 3 & 4\end{array}$

17. Trembling

$\begin{array}{lllll}0 & 1 & 2 & 3 & 4\end{array}$

18. Feeling that most people cannot be trusted

$\begin{array}{lllll}0 & 1 & 2 & 3 & 4\end{array}$

19. Poor appetite

$\begin{array}{lllll}0 & 1 & 2 & 3 & 4\end{array}$


20. Crying easily

$\begin{array}{lllll}0 & 1 & 2 & 3 & 4\end{array}$

21. Feeling shy or uneasy with the opposite sex

$\begin{array}{lllll}0 & 1 & 2 & 3 & 4\end{array}$

22. Feelings of being trapped or caught

$\begin{array}{lllll}0 & 1 & 2 & 3 & 4\end{array}$

23. Suddenly scared for no reason

$\begin{array}{lllll}0 & 1 & 2 & 3 & 4\end{array}$

24. Temper outbursts that you could not control

$\begin{array}{lllll}0 & 1 & 2 & 3 & 4\end{array}$

25. Feeling afraid to go out of your house alone

$\begin{array}{lllll}0 & 1 & 2 & 3 & 4\end{array}$

26. Blaming yourself for things

$\begin{array}{lllll}0 & 1 & 2 & 3 & 4\end{array}$

27. Pains in lower back

$\begin{array}{lllll}0 & 1 & 2 & 3 & 4\end{array}$

28. Feeling blocked in getting things done

$\begin{array}{lllll}0 & 1 & 2 & 3 & 4\end{array}$

29. Feeling lonely

$\begin{array}{lllll}0 & 1 & 2 & 3 & 4\end{array}$

30. Feeling blue

$\begin{array}{lllll}0 & 1 & 2 & 3 & 4\end{array}$


31. Worrying too much about things

$\begin{array}{lllll}0 & 1 & 2 & 3 & 4\end{array}$

32. Feeling no interest in things

$\begin{array}{lllll}0 & 1 & 2 & 3 & 4\end{array}$

33. Feeling fearful

$\begin{array}{lllll}0 & 1 & 2 & 3 & 4\end{array}$

34. Your feelings being easily hurt

$\begin{array}{lllll}0 & 1 & 2 & 3 & 4\end{array}$

35. Other people being aware of your private thoughts

$\begin{array}{lllll}0 & 1 & 2 & 3 & 4\end{array}$

36. Feeling others do not understand you or are unsympathetic

$\begin{array}{lllll}0 & 1 & 2 & 3 & 4\end{array}$

37. Feeling that people are unfriendly or dislike you

$\begin{array}{lllll}0 & 1 & 2 & 3 & 4\end{array}$

38. Having to do things very slowly to insure correctness

$\begin{array}{lllll}0 & 1 & 2 & 3 & 4\end{array}$

39. Heart pounding or racing

$\begin{array}{lllll}0 & 1 & 2 & 3 & 4\end{array}$

40. Nausea or upset stomach

$\begin{array}{lllll}0 & 1 & 2 & 3 & 4\end{array}$

41. Feeling inferior to others

$\begin{array}{lllll}0 & 1 & 2 & 3 & 4\end{array}$


42. Soreness of your muscles

$\begin{array}{lllll}0 & 1 & 2 & 3 & 4\end{array}$

43. Feeling that you are watched or talked about by others

$\begin{array}{lllll}0 & 1 & 2 & 3 & 4\end{array}$

44. Trouble falling asleep

$\begin{array}{lllll}0 & 1 & 2 & 3 & 4\end{array}$

45. Having to check and double-check what you do

$\begin{array}{lllll}0 & 1 & 2 & 3 & 4\end{array}$

46. Difficulty making decisions

$\begin{array}{lllll}0 & 1 & 2 & 3 & 4\end{array}$

47. Feeling afraid to travel on buses, subways, or trains

$\begin{array}{lllll}0 & 1 & 2 & 3 & 4\end{array}$

48. Trouble getting your breath

$\begin{array}{lllll}0 & 1 & 2 & 3 & 4\end{array}$

49. Hot or cold spells

$\begin{array}{lllll}0 & 1 & 2 & 3 & 4\end{array}$

50. Having to avoid certain things, places, or activities because they frighten you

$\begin{array}{lllll}0 & 1 & 2 & 3 & 4\end{array}$

51. Your mind going blank

$\begin{array}{lllll}0 & 1 & 2 & 3 & 4\end{array}$

52. Numbness or tingling in parts of your body

$\begin{array}{lllll}0 & 1 & 2 & 3 & 4\end{array}$


53. A lump in your throat

$\begin{array}{lllll}0 & 1 & 2 & 3 & 4\end{array}$

54. Feeling hopeless about the future

$\begin{array}{lllll}0 & 1 & 2 & 3 & 4\end{array}$

55. Trouble concentrating

$\begin{array}{lllll}0 & 1 & 2 & 3 & 4\end{array}$

56. Feeling weak in parts of your body

$\begin{array}{lllll}0 & 1 & 2 & 3 & 4\end{array}$

57. Feeling tense or keyed up

$\begin{array}{lllll}0 & 1 & 2 & 3 & 4\end{array}$

58. Heaving feelings in your arms or legs

$\begin{array}{lllll}0 & 1 & 2 & 3 & 4\end{array}$

59. Thoughts of death or dying

$\begin{array}{lllll}0 & 1 & 2 & 3 & 4\end{array}$

60. Overeating

$\begin{array}{lllll}0 & 1 & 2 & 3 & 4\end{array}$

61. Feeling uneasy when people are watching or talking about you

$\begin{array}{lllll}0 & 1 & 2 & 3 & 4\end{array}$

62. Having thoughts that are not your own

$\begin{array}{lllll}0 & 1 & 2 & 3 & 4\end{array}$

63. Having urges to beat, injure, or harm someone

$\begin{array}{lllll}0 & 1 & 2 & 3 & 4\end{array}$


64. Awakening in the early morning

$\begin{array}{lllll}0 & 1 & 2 & 3 & 4\end{array}$

65. Having to repeat the same actions such as touching, counting, or washing

$\begin{array}{lllll}0 & 1 & 2 & 3 & 4\end{array}$

66. Sleep that is restless or disturbed

$\begin{array}{lllll}0 & 1 & 2 & 3 & 4\end{array}$

67. Having urges to break or smash things

$\begin{array}{lllll}0 & 1 & 2 & 3 & 4\end{array}$

68. Having ideas or beliefs that others do not share

$\begin{array}{lllll}0 & 1 & 2 & 3 & 4\end{array}$

69. Feeling very self-conscious with others

$\begin{array}{lllll}0 & 1 & 2 & 3 & 4\end{array}$

70. Feeling uneasy in crowds, such as shopping or at a movie

$\begin{array}{lllll}0 & 1 & 2 & 3 & 4\end{array}$

71. Feeling everything is an effort

$\begin{array}{lllll}0 & 1 & 2 & 3 & 4\end{array}$

72. Spells of terror or panic

$\begin{array}{lllll}0 & 1 & 2 & 3 & 4\end{array}$

73. Feeling uncomfortable about eating or drinking in public

$\begin{array}{lllll}0 & 1 & 2 & 3 & 4\end{array}$

74. Getting into frequent arguments

$\begin{array}{lllll}0 & 1 & 2 & 3 & 4\end{array}$


75. Feeling nervous when you are left alone

$\begin{array}{lllll}0 & 1 & 2 & 3 & 4\end{array}$

76. Others not giving you proper credit for your achievements

$\begin{array}{lllll}0 & 1 & 2 & 3 & 4\end{array}$

77. Feeling lonely even when you are with people

$\begin{array}{lllll}0 & 1 & 2 & 3 & 4\end{array}$

78. Feeling so restless you couldn't sit still

$\begin{array}{lllll}0 & 1 & 2 & 3 & 4\end{array}$

79. Feelings of worthlessness

$\begin{array}{lllll}0 & 1 & 2 & 3 & 4\end{array}$

80. The feeling that something bad is going to happen to you

$\begin{array}{lllll}0 & 1 & 2 & 3 & 4\end{array}$

81. Shouting or throwing things

$\begin{array}{lllll}0 & 1 & 2 & 3 & 4\end{array}$

82. Feeling afraid you will faint in public

$\begin{array}{lllll}0 & 1 & 2 & 3 & 4\end{array}$

83. Feeling that people will take advantage of you if you let them

$\begin{array}{lllll}0 & 1 & 2 & 3 & 4\end{array}$

84. Having thoughts about sex that bother you a lot

$\begin{array}{lllll}0 & 1 & 2 & 3 & 4\end{array}$

85. The idea that you should be punished for your sins

$\begin{array}{lllll}0 & 1 & 2 & 3 & 4\end{array}$


86. Thoughts and images of a frightening nature

$\begin{array}{lllll}0 & 1 & 2 & 3 & 4\end{array}$

87. The idea that something serious is wrong with your body

$\begin{array}{lllll}0 & 1 & 2 & 3 & 4\end{array}$

88. Never feeling close to another person

$\begin{array}{lllll}0 & 1 & 2 & 3 & 4\end{array}$

89. Feelings of guilt

$\begin{array}{lllll}0 & 1 & 2 & 3 & 4\end{array}$

90. The idea that something is wrong with your mind

$\begin{array}{lllll}0 & 1 & 2 & 3 & 4\end{array}$




\section{APPENDIX C - Suicidal Behaviors Questionnaire-Revised}

Instructions: Please select the option beside the statement or phrase that best applies to you.

1. Have you ever thought about or attempted to kill yourself?

$0=$ Never

$1=$ It was just a brief passing thought

$2=$ I have had a plan at least once to kill myself but did not try to do it

$3=$ I have had a plan at least once to kill myself and really wanted to do it

$4=$ I have attempted to kill myself, but did not really want to die

$5=$ I have attempted to kill myself, and really hoped to die

2. How often have you thought about killing yourself in the past year?

$0=$ Never

$1=$ Rarely (1 time)

$2=$ Sometimes $(2$ times $)$

$3=$ Often (3-4 times)

$4=$ Very often ( 5 or more time)

3. Have you ever told someone that you were going to commit suicide or that you might do it?

$0=$ No

$1=$ Yes, but for only one short period of time

$2=$ Yes, for more than one short period of time

4. How likely is it that you will attempt suicide someday?

$0=$ Never

$1=$ No chance at all

$3=$ Rather unlikely

$4=$ Unlikely

$5=$ Likely

$6=$ Rather likely

$7=$ Very likely 


\section{APPENDIX D - Five Factor Model Rating Form}

Please describe yourself on a 1 to 5 scale on each of the following 30 personality traits, where 1 is extremely low (i.e., extremely lower than the average person), 2 is low, 3 is neither high nor low (i.e., does not differ from the average person), 4 is high and 5 is extremely high. Use any number from 1 to 5 . Please provide a rating for all 30 traits.

For example on the first trait (anxiousness), a score of 1 would indicate that you think you are extremely low in anxiousness (i.e., relaxed, unconcerned, cool). A score of 2 would indicate that you think you are low in anxiousness (lower than the average person, but not extremely low). A score of 5 would indicate that you think you are extremely high in anxiousness (i.e., fearful, apprehensive); a score of 4 would indicate you think you are higher than the average person in anxiousness, but not extremely high. A score of 3 would indicate that you think you are neither high nor low in anxiousness (does not differ from the average person) or that you are unable to decide. Circle the number that applies to the individual for each of the 30 traits.

\section{5= Extremely high $\quad 4=$ High $\quad 3=$ Neither high nor low $\quad 2=$ Low $\quad$ 1=Extremely Low}

\section{Neuroticism versus Emotional Stability:}

1. Anxiousness (fearful, apprehensive)

2. Angry Hostility (angry, bitter)

3. Depressiveness (pessimistic, glum)

4. Self-consciousness (timid, embarrassed) shameless)

5. Impulsivity (tempted, urgency)

6. Vulnerability (helpless, fragile) unflappable)

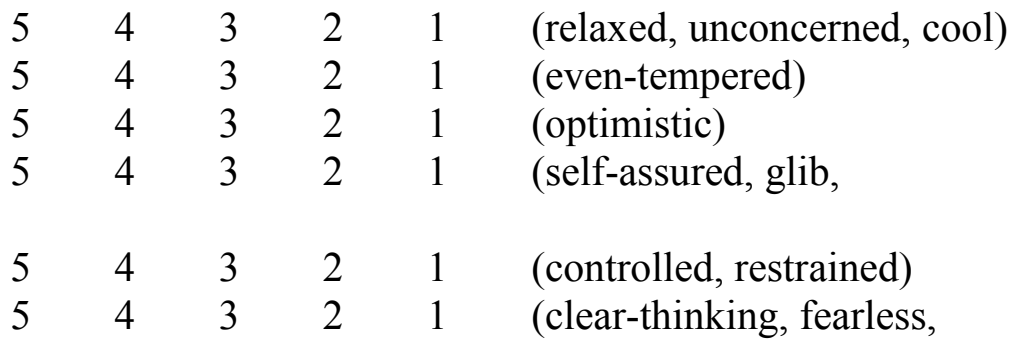

Extraversion versus Introversion:

7. Warmth (cordial, affectionate, attached)

8. Gregariousness (sociable, outgoing)

9. Assertiveness (dominant, forceful)

10. Activity (vigorous, energetic, active)

11. Excitement-Seeking (reckless, daring)

12. Positive Emotions (high-spirited)

$\begin{array}{lllll}5 & 4 & 3 & 2 & 1 \\ 5 & 4 & 3 & 2 & 1 \\ 5 & 4 & 3 & 2 & 1 \\ 5 & 4 & 3 & 2 & 1 \\ 5 & 4 & 3 & 2 & 1 \\ 5 & 4 & 3 & 2 & 1\end{array}$

(cold, aloof, indifferent)

(withdrawn, isolated)

(unassuming, quiet, resigned)

(passive, lethargic)

(cautious, monotonous, dull)

(placid, anhedonic)

\section{Openness versus Closedness to one's own Experience:}

\begin{tabular}{|c|c|c|c|c|c|c|}
\hline 13. Fantasy (dreamer, unrealistic, imaginative) & 5 & 4 & 3 & 2 & 1 & (practical, concrete) \\
\hline $\begin{array}{l}\text { 14. Aesthetics (aberrant interests, aesthetic) } \\
\text { interests ) }\end{array}$ & 5 & 4 & 3 & 2 & 1 & (uninvolved, no aesthetic \\
\hline $\begin{array}{l}\text { 15. Feelings (self-aware) } \\
\text { alexythymic) }\end{array}$ & 5 & 4 & 3 & 2 & 1 & (constricted, unaware, \\
\hline $\begin{array}{l}\text { 16. Actions (unconventional, eccentric) } \\
\text { habitual, stubborn) }\end{array}$ & 5 & 4 & 3 & 2 & 1 & (routine, predictable, \\
\hline 17. Ideas (strange, odd, peculiar, creative) &  & 4 & & & & (pragmatic, rigid) \\
\hline 18. Values (permissive, broad-minded) & 5 & 4 & 3 & 2 & 1 & (traditional, inflexible, \\
\hline
\end{tabular}
dogmatic) 


\section{Agreeableness versus Antagonism:}

19. Trust (gullible, naïve, trusting) suspicious, paranoid)

20. Straightforwardness (confiding, honest) deceptive)

21. Altruism (sacrificial, giving) exploitative)

22. Compliance (docile, cooperative) aggressive)

23. Modesty (meek, self-effacing, humble)

24. Tender-Mindedness (soft, empathetic) $\begin{array}{llllll}5 & 4 & 3 & 2 & 1 & \text { (skeptical, cynical, }\end{array}$

$\begin{array}{lllll}5 & 4 & 3 & 2 & 1\end{array}$ (cunning, manipulative,

$\begin{array}{llllll}5 & 4 & 3 & 2 & 1\end{array}$ (stingy, selfish, greedy,

$\begin{array}{llllll}5 & 4 & 3 & 2 & 1\end{array}$ (oppositional, combative,

$\begin{array}{llllll}5 & 4 & 3 & 2 & 1 & \text { (confident, boastful, arrogant) }\end{array}$

$\begin{array}{llllll}5 & 4 & 3 & 2 & 1 & \text { (tough, callous, ruthless) }\end{array}$

\section{Conscientiousness versus Undependability:}

\begin{tabular}{|c|c|c|c|c|c|}
\hline 25. Competence (perfectionistic, efficient) & 4 & 3 & 2 & 1 & (lax, negligent) \\
\hline $\begin{array}{l}\text { 26. Order (ordered, methodical, organized) } \\
\text { sloppy) }\end{array}$ & 4 & 3 & 2 & 1 & (haphazard, disorganized, \\
\hline $\begin{array}{l}\text { 27. Dutifulness (rigid, reliable, dependable) } \\
\text { unethical) }\end{array}$ & 4 & 3 & 2 & 1 & (casual, undependable, \\
\hline 28. Achievement (workaholic, ambitious) & 4 & 3 & 2 & 1 & (aimless, desultory) \\
\hline 29. Self-Discipline (dogged, devoted) & 4 & 3 & 2 & 1 & (hedonistic, negligent) \\
\hline 30. Deliberation (cautious, ruminative, reflective) 5 & 4 & 3 & 2 & 1 & (hasty, careless, rash) \\
\hline
\end{tabular}




\section{APPENDIX E-Logistic Regression of FFMRF}

Logistic regression analysis predicting 138 participants' status as a cyberbully victim or control group participant using the Five Factor Model Rating Form (FFMRF)

\begin{tabular}{|c|c|c|c|c|c|c|}
\hline Variable & $B$ & $S E$ & Wald Statistic & $d f$ & $p$ & Odds ratio \\
\hline Neuroticism & .19 & .054 & 12.13 & 1 & .000 & 1.21 \\
\hline Extraversion & .23 & .069 & 11.46 & 1 & .001 & 1.26 \\
\hline Openness & .00 & .074 & .002 & 1 & .967 & 1.00 \\
\hline Agreeableness & -.16 & .072 & 4.64 & 1 & .031 & .86 \\
\hline Conscientiousness & .02 & .055 & .131 & 1 & .718 & 1.020 \\
\hline Test & & & $\chi^{2}$ & $d f$ & $p$ & \\
\hline \multicolumn{7}{|l|}{ Overall model evaluation } \\
\hline Likelihood ratio test & & & 22.23 & 5 & .000 & \\
\hline \multicolumn{7}{|l|}{ Goodness-of-fit Test } \\
\hline Hosmer \& Lemeshow & & & 4.98 & 8 & .760 & \\
\hline
\end{tabular}

Note. Cox and Snell $\mathrm{R}^{2}=.15$. Nagelkerke $\mathrm{R}^{2}=.20$. Nonsignificant value for the HosmerLemeshow test is desired and suggests the model fit the data well. 